This is a peer-reviewed, accepted author manuscript of the following research article: Mukendi, A., Davies, I., McDonagh, P., \& Glozer, S. (2020). Sustainable fashion: current and future research directions. European Journal of Marketing. https://doi.org/10.1108/EJM-02-2019-0132

\title{
Sustainable Fashion: Current and Future Research Directions
}

\begin{abstract}
Purpose:

The sustainable fashion literature is fragmented across the management discipline, leaving the path to a sustainable fashion future unclear. As of yet, there has been no attempt to bring these insights together, or to more generally explore the question of "what do we know about sustainable fashion and where do we go from here?" The aim of this review paper is to bring together the sustainable fashion field, identifying opportunities for societal impact and further research.
\end{abstract}

\section{Design/methodology/approach:}

A systematic literature review was conducted from the first appearances of sustainable fashion in the management literature in 2000 up to articles published in June 2019, resulting in 465 included articles.

\section{Findings:}

The results illustrate that sustainable fashion research is largely defined by two approaches: pragmatic change and radical change. Our findings reveal seven research streams that span across the discipline to explore how organisational and consumer habits can be shaped for the future.

\section{Research limitations/implications:}

What is known about sustainable fashion is constantly evolving with a variety of contributions from multiple fields. The paper aims to provide a representative sample of the state of sustainable fashion in management literature to date, but space limitations make a full exploration of all contributions impossible.

\section{Practical implications:}

This review provides decision makers with insights that have been synthesised from across the management field.

\section{Originality/value:}

This review identifies knowledge gaps and informs managerial decision making in the field, particularly through serving as a foundation for further research.

Keywords: Sustainable Fashion; Ethical Fashion; Marketing Ethics; Sustainable Business Models 


\section{Introduction}

In the last year, the media spotlight has been firmly cast on the fashion industry. Far from celebrating an industry that represents two percent of the world's Gross Domestic Product (GDP), and is valued at three trillion US Dollars (FashionUnited, 2018), a critical spotlight has brought into focus a whole host of fashion sustainability ills. Be it unwanted clothes going up in smoke at Burberry, or documentaries such as 'Fashion's Dirty Secrets' the devastating social impact of the world's fashion industry has been brought into the mainstream, calling into question traditional fashion consumption and production practices. To deal with these issues, sustainable fashion (SF) has emerged as a broad term for clothing and behaviours that are in some way less damaging to people and/or the planet. SF - and related practices of ethical fashion, eco-fashion, and slow fashion - highlights alternative approaches to fashion and presents a challenge to the rest of the industry by suggesting that 'fast fashion needs to slow down' (Dory, 2018). Yet, while the practical climate for SF develops at a rapid pace through an increasing number of start-up accelerators, clothes swapping events, consumer-facing scoring and measurement tools, and civil society organisations, the academic literature has been slow to define and conceptualise SF, despite some notable developments (e.g. Fletcher, 2008; Henninger et al., 2016).

It is against this backdrop that this review paper is situated. At present, a limited body of research explores the phenomena of SF beyond the micro-institutional or individual consumer level (Ekström and Salomonson, 2014; Ertekin and Atik, 2015). Previous literature reviews that have made headway, have focussed on only specific aspects of SF: e.g. supply chains (Karaosman et al., 2016; Köksal et al., 2017; Strähle and Müller, 2017), consumers (Tey et al., 2018) and retailing (Yang et al., 2017). As of yet, these insights have not been systematically brought together 
and the question of "what do we know about sustainable fashion and where do we go from here?" remains unanswered. At a time when interest in SF as a research domain of vital societal interest is mounting (Johnson et al., 2013; Strähle and Müller, 2017), this paper provides a review which is intentionally provocative and designed to promote further development of the field, both academically and practically. It encourages researchers to connect theory to practice, to ask relevant questions, and to engage with the public to drive a more sustainable future for fashion.

This paper makes two important contributions. First, this paper is the first to systematically draw together the different aspects of SF in a cross-disciplinary, holistic and coherent way, building on key scholarship (e.g. Karaosman et al., 2016; Köksal et al., 2017; Yang et al., 2017). Our analysis is not limited to a particular discipline or practice but instead identifies what is known and what is yet to be known about SF across the management discipline. As a result, the paper offers a working definition of SF: the variety of means by which a fashion item or behaviour could be perceived to be more sustainable, including (but not limited to) environmental, social, slow fashion, reuse, recycling, cruelty-free and anti-consumption and production practices. It also offers a conceptual model to aid the reader in integrating SF across different domains. Second, this review serves as a foundation for identifying knowledge gaps and informing managerial decision making in the field. In this respect it considers both the research challenges of sustainable consumption (McDonagh et al., 2011), as well as the incorporation of production into this discourse and what this means for the emergence of 'Sustainable Consumption \& Production (SC\&P)' as a research field (McDonagh et al., 2011).

This paper first discusses the systematic literature review methodology, before defining SF and conceptualising SF. It then moves on to unpacking two approaches to understanding SF: 
pragmatic and radical change. The paper concludes with a discussion and future research agenda, before providing concluding remarks and managerial implications.

\section{Research Design and Methodology}

This study adopts a meta-narrative systematic literature review approach to synthesise SF literature across the management discipline. Meta-narrative syntheses integrate qualitative and quantitative works while maintaining the integrity of the original work (Denyer and Tranfield, 2006; Thomas and Harden, 2008; Barnett-Page and Thomas, 2009). It is a useful approach for understanding complex issues, especially in emerging fields like SF, where the literature is still developing (Denyer and Tranfield, 2006). Utilising Denyer's eight-step process to conducting a systematic review (see Denyer and Pilbeam, 2013, drawing on Denyer and Tranfield 2009), the methodology is structured around the key steps of: 1) developing a protocol, 2) conducting a comprehensive search, 3) screening titles and abstracts, 4) developing explicit selection criteria, 5) evaluating results, 6) extracting and synthesising information, 7) reporting results, and 8) informing research and policy. Denyer and Tranfield's (2009) process has been specifically designed for management studies and emphasises informing theory and practice; key goals of this paper. The following section summarises the steps into two phases, an outline of the review process (phase 1: Denyer and Pilbeam's steps 1-4) and a discussion of how the review was conducted (phase 2: Denyer and Pilbeam's steps 5-8).

\section{Phase 1: Denyer's Steps 1-4-Review protocol to sample selection}

A preliminary research protocol was developed as a guideline for conducting the review based around the question, "what is $S F$ ?". A scoping study revealed ambiguity around what constitutes SF, with conversations fragmented across disciplines (Johnson et al., 2013). Systematic 
reviews in management are an iterative process (Tranfield et al., 2003), especially when applying meta-narrative synthesis (Denyer and Tranfield, 2006). Considering this, the protocol was adjusted to answer, "what do we know about SF in management?".

In step 2, to ensure that a wide variety of sources would be represented in the review, a time limit was not imposed. The comprehensive literature search included research from the first studies on SF, and related terms, in management in 2000 until June 2019 (Tranfield et al., 2003, Denyer and Tranfield, 2009). Because research relevant to management is published in a variety of journals, nine of the major databases were selected. Emerald Insight, ScienceDirect, Web of Science, ABI/Inform, SAGE, Springer, Taylor and Francis, Business Source Complete, and Scopus were searched between October to December 2017 with updates conducted in June 2019 to account for more recent publications. In each database the keywords: 'sustainable fashion', 'ethical fashion,' 'slow fashion,' 'eco fashion,' and 'green fashion' were searched because these terms are used synonymously with SF (Thomas, 2008; Bly et al., 2015; Henninger et al., 2016). Databases such as Researchgate and Google Scholar were used as secondary databases if a document could not be found in full-text in the first instance.

The comprehensive search found more than 6,200 articles (including duplicates) were found across the nine databases. The initial screening of titles and abstracts (step 3) included articles from every discipline to conceptualise a holistic definition of SF; papers around material composition were included, for instance. The protocol was therefore further refined through the use of inclusion and exclusion criteria (step 4) to include papers of relevance to the management discipline specifically (see Table 1). Initial screening reduced the number of relevant articles to 1,315 , excluding duplicates. The authors regarded this number cautiously as many of the papers used terms such as 'sustainable fashion' or 'ethical fashion' peripherally, resulting in false 
positives that were excluded in step 4 through the exclusion of articles without a primary focus on sustainable fashion (see Figure 1). This study includes a wide range of sources including empirical and conceptual journal articles, conference papers, and book chapters. The full texts were then reviewed and 465 studies were selected for inclusion. To accommodate EJM word limits, a full list of articles can be obtained from the authors on request.

[Insert Table 1 around here]

[Insert Figure 1 around here]

\section{Phase 2: Denyer's Steps 5-8 - Conducting the review}

In step 5 selected articles were imported into Mendeley while in step 6 details of the selected studies were extracted into a standardised database. Following the meta-narrative synthesis process, each article was primarily assessed for its internal validity (Barnett-Page and Thomas, 2009) and the database was regularly discussed amongst the co-authors. Studies were broadly assessed using Denyer and Pilbeam's (2013) criteria, however, all works were assessed through methods appropriate for the publication (i.e. journal article, book chapter, etc.) and its research design. An interpretative approach was taken to synthesise the various sources of data into a narrative of what is known about SF today (see Table 2). Step 7 (report of results) can be found in the findings section, and step 8 (informing research and policy) can be found in the discussion and conclusion of this paper.

[Insert Table 2 around here]

\section{Findings}




\section{Defining Sustainable Fashion}

SF really started to appear in the management literature around 2008 with pioneering works such as Fletcher (2008), Beard (2008), De Brito (2008), and Clark (2008). However, more than 10 years on, an agreed upon definition of SF is still elusive (Henninger et al., 2016; Reimers et al., 2016). Offering a precise definition is beyond the scope of this paper, particularly given the fluid and evolving nature of sustainability in fashion, and also the recognition of limitations in identifying an 'absolute' SF item or practice. This is largely due to the subjectivity that surrounds sustainability as being, "intuitively understood, yet has no coherent definition" (Henninger et al., 2016, p.402). This section does, however, offer a working definition that pertains to the parameters of SF; what it is, and what it is not. This paper forwards the view that SF includes the variety of means by which a fashion item or behaviour could be perceived to be more sustainable, including (but not limited to) environmental, social, slow fashion, reuse, recycling, cruelty free and anticonsumption and production practices.

This working definition was formulated through a synthesis of the emerging definitions present within the literature to date. For instance, several studies have attempted to define SF from a consumer perspective (Joergens, 2006; Hill and Lee, 2012; Jung and Jin 2014; Jung and Jin, 2015; Reimers et al., 2016). Other researchers have adopted a more macro approach, incorporating infrastructure, norms, and wider stakeholders into their definitions (see Thomas, 2008; Haug and Busch, 2016). It is worth noting that while overlaps exist between SF, ethical fashion, eco-fashion, slow fashion, and green fashion research, in practice, these terms do have different connotations, and rarely intersect. This was touched upon by Reimers et al. (2016), who explored different conceptions of ethical fashion between researchers and consumers. Although academia views SF as including both social and environmental aspects, consumers primarily define SF as using 
environmentally friendly language (Hill and Lee, 2012), although this is not without contradiction (Bly et al., 2015). Consumers simply expect brands to do the right thing, to act morally and uphold industry standards (Reimers et al., 2016).

As illustrated in Table 3, SF is not academically synonymous with slow fashion (Pookulangara and Shephard, 2013) or eco-fashion (Carey and Cervellon, 2014). SF is most closely related to ethical fashion, which is reflected in the overlap of the literature and definitions (Lundblad and Davies, 2015). Joergens (2006, p. 361) suggests that ethical fashion can be defined as: "clothes that incorporate fair trade principles with sweatshop-free labour conditions while not harming the environment or workers by using biodegradable and organic cotton," demonstrating ethical fashion to be a process as well as a product. However, SF has transformed the "while" into the more flexible "and/or" (Goworek et al., 2012; Henninger et al., 2016). For instance, Goworek et al. (2012, p. 938) base their definition of SF on Joergens' (2006) definition, however, they have expanded the scope of what might be considered SF to, "clothing which incorporates one or more aspects of social or environmental sustainability, such as Fair Trade manufacturing or fabric containing organically-grown raw material." This sentiment is also shared by Henninger et al. (2016), who suggest that SF incorporates environmentally friendly raw materials and/or a more socially responsible means of production, and Lundblad and Davies (2015, p.150) who define SF as an attempt to, "correct a variety of perceived wrongs in the fashion industry including animal cruelty, environmental damage, and worker exploitation." Here the keyword is "perceived" as it illustrates the selective nature of SF. In sum, unlike previous definitions of ethical or eco-fashion, the emergent definitions of SF that this paper draws upon are less specific over time, and more malleable in offering consumers and producers the option to select which aspects of sustainability they implement. This does however leave a broad scope for both academics and practitioners to 
make competing claims for SF, which may intersect, or even conflict with each other; a topic explored further below.

[Insert Table 3 around here]

\section{Conceptualising Sustainable Fashion}

The SF literature can be segmented into two broad approaches: pragmatic change and radical change (see Burrell and Morgan, 1979). Building on Doherty et al.'s (2013) definition of pragmatic consumption, pragmatic change relates to the use of mainstream retail and marketing methods to grow SF impact. Pragmatic change approaches work within the system, using the dominant social paradigm (DSP) around consumption and production to encourage stakeholders to "do better", adopting familiar language and practices (Prothero et al., 2010; McDonagh and Prothero, 2015). For example, brands such as People Tree and Patagonia utilise physical stores, e-retailing, advertising and social media marketing just as their non-sustainable counterparts do, despite their goals being markedly different. Radical change, on the other hand, relates to more transformative practices that work outside of, or counter and challenge the system and mainstream consumerist culture (Doherty et al., 2013). Such examples include anti-consumption, pioneering innovative business models, and investing in individuals (such as through educational programmes around clothing repair) to encourage social change.

In reviewing the current literature it is clear that both pragmatic and radical change can occur throughout the continuum from SF production to consumption (see Figure 3). A producer “convert[s] a collection of raw materials into a finished product" for use in the market (Davies, 2014). Consumption is defined as, "the acquisition, usage, and disposition of products," (Holbrook, 1987, p.128). Products in both instances refer to "goods, services, ideas, events, or any other 
entities that can be acquired, used, or disposed of in ways that potentially provide value," (Holbrook, 1987, p.128). This definition implies that consumption is not just the purchase of items but also ideas or behaviours.

In commencing this systematic review we provide the following Figures and Tables exploring the dominant fields of extant SF literature. Figure 2 demonstrates the growth of research across the SF field in general. Next, Figure 3 is a new conceptual framework that maps the field of SF across seven clusters that emerged from the analysis: supply chains, social retail marketing, consumer behaviour, consumer practices and communities, social marketing interventions, future leaders, and sustainable business models, which have been organised along the radical-pragmatic change, and production-consumption continua. This framework aims to help the reader understand the complexities and challenges of SF theory and practice. Table 4 offers more detailed descriptions of each of these clusters, and Table 5 illustrates the methodological approaches most prevalent in each cluster.

\section{[Insert Figure 2 around here] \\ [Insert Figure 3 around here] \\ [Insert Table 4 around here] \\ [Insert Table 5 around here]}

Although 465 articles have been incorporated into this review, 500 are represented across the matrix (Figure 3) to accommodate articles which addressed multiple fields. The size of the bubbles is also representative of the relative 'weight' of research in the field to date in this area. It is important to note that the number of articles in the SF management literature has increased steadily since 2001, but rapidly since 2012, peaking in 2017, and falling in 2018 (Figure 2). Why 
there has been such a rapid increase and then decrease is difficult to pinpoint because of the academic publishing cycle but crises such as the factory collapse in Rana Plaza (2013), the launch of Fashion Revolution Week (2014), and documentaries such as The True Cost (2015), may have contributed to the rise. There are no notable temporal patterns across the seven individual clusters identified through our analysis, but as shown in Table 4 and Figure 3, clusters such as future leaders, social marketing interventions, and consumer practices and communities, have a much lower volume, illustrating the necessity of further research into more radical forms of SF practices. The literature so far is dominated by Western voices (the USA and Europe) which is unsurprising considering these countries purchased more than 24 billion items of clothing in 2017 (Common Objective, 2018). China has the highest quantity of clothing purchased, estimated at 40 billion, but this same dominance is not reflected in the literature. The literature could greatly benefit from more nuanced analysis around subcultures in the West and other cultures around the world, and how they relate to SF. Additional research is also needed into how people experience the effects of SF, or lack thereof, so that researchers and practitioners can have more nuanced view into the problems they are attempting to solve.

Across these different clusters, several methodological approaches are used (Table 5). Although there appears to be a balance between qualitative and quantitative research in the SF literature, quantitative research dominates the pragmatic consumer behaviour cluster, usually involving the application of tried and tested theories of rational-cognitive decision-making commonly applied to other sustainable consumption contexts (such as food and energy usage). Conversely, qualitative work is more embedded in the radical change and supply chain studies. However, from both a supply-chain and radical change perspective, SF is conceptualised as a unique context in need of further theory development. These issues are explored below. 


\section{Sustainable Fashion: A Pragmatic View on Production and Consumption}

Pragmatic change approaches operate within the DSP around consumption and production (Prothero et al., 2010; McDonagh and Prothero, 2015). In this tradition, there are contributions clustered into supply chain, social retail marketing, and consumer behaviour research streams, which are discussed below.

\section{Supply Chain}

Supply chain refers to the movement of raw materials through design, fabrication, and manufacturing to produce a SF product. The supply chain is an integral part of making a product more sustainable (Henninger et al., 2015; Lee, 2017), and thus is a vital field for SF practice, both within small (and micro) firms, as well as large, global multinationals. In this section we look first at the emergent literature on micro-organisations, followed by an exploration of brand owners, finishing with a review of the very limited research into garment manufacturers themselves.

The supply chains of micro-organisations, such as the Danish fashion company Noir (Black and Anderson, 2010), are the most common context in this domain as they occupy a unique position; they have sustainability at their core but implement it with considerably fewer resources and structure than more established brands (Caniato et al., 2012; Henninger et al., 2015; Di Benedetto, 2017). Their size has enabled them to develop a culture around sustainability and make more attempts to ensure transparency throughout their supply chains (Caniato et al., 2012; Goworek, 2011; Bouzon and Govindan, 2015; Henninger et al., 2015; Joy and Peña, 2017). Although the size of smaller brands can be advantageous, micro-organisations often lack power 
and influence in the market (Kogg, 2003; Black and Anderson, 2010; Caniato et al., 2012). With limited budgets and minimum order quantities, micro-SF brands are forced to make a variety of trade-offs to manage costs and increase profitability (Pessôa et al., 2015; DiVito and Bohnsack, 2017). For example, in times of economic uncertainty, sustainability initiatives are often cut (Perry et al., 2014). Moreover, the literature has shown that micro-organisations may not measure the impacts of their sustainable interventions, nor do they seek certification; therefore, it is unclear how they measure their impact, determine their sustainability and communicate this to other stakeholders (Henninger et al., 2015; Moon et al., 2015). Researchers should be wary of over generalising the results gained from these cases or setting them as exemplars for the industry as the sustained environmental impact of their models is still unclear. Yet, it is worth noting that micro-organisations can create useful societal debate and influence larger organisations to transform the fashion industry through a 'David' (micro-organisations) and 'Green Goliath' (global brands) approach (Molderez and De Landtsheer, 2015). Further theory development would be helpful in this area, moving away from the broadly descriptive, or purely conceptual, approaches undertaken to date.

Regarding global brands, governance, either by non-governmental organisations (NGOs) (e.g. Jastram and Schneider, 2015 and Ciarapica et al., 2017) or through legislation (e.g. Ma et al., 2016; Niu et al., 2017 and Oelze, 2017), has been investigated as a method to support and enforce companies to implement SF practices. Niu et al. (2017) suggest government regulations that provide subsidies may encourage retailers to transform how they procure garments. Beyond governance, the literature suggests manufacturers should adopt various SF practices such as: utilising environmentally friendly dyes (Fulton and Seung-Eun, 2013), adopting innovative procurement strategies and life cycle analysis (Pui-Yan Ho and Choi, 2012; Resta et al., 2013; 
Wang and Shen 2017; Niu et al., 2017; Cimatti et al., 2017; Roos et al., 2017), coordinating closedloop supply chains and developing less wasteful philosophies (Pui-Yan Ho and Choi, 2012; Bouzon and Govindan, 2015; Nagurney and Yu, 2012; Strähle and Schnaidt, 2017; Dissanayake et al., 2017), localising operations (Fulton and Seung-Eun, 2013; Shih and Agrafiotis, 2018), and upcycling (Paras and Curteza, 2018), to tackle sustainability in supply chains. While such ideas are useful in stimulating creativity, strategic insight into actual supply chain recommendations and decision-making is lacking, as is quality research into the market-based impacts of making such changes to competitive positioning. Moreover, for the textile industry, one with such scope and power, there are surprisingly few studies exploring the means through which companies optimise the sustainability of their upstream operations or how they motivate suppliers to transform.

Interestingly, even within the supply chain research on SF, it is often the retailers and brand owners that are the focus of research, rather than the suppliers themselves. With brands coming under fire for not ensuring safe working conditions in the third-party factories they work with, it is no surprise that few papers have been given access to organisations to analyse the supply chain from the supplier perspective (e.g. Kogg, 2003; Oelze, 2017; Kim and Zorola, 2018). This limits our understanding of the ways in which brands can drive, or be complicit in, unsustainable behaviours. Additionally, suppliers face an asymmetric power situation (Kim and Zorola, 2018) whereby brands make demands and set prices. Further understanding the supplier perspective is imperative to facilitating more sustainable supply chains. Despite codes of conduct developed by brands (Turker and Altunas, 2014), suppliers are the ones who ultimately decide whether to enforce them (Köksal et al., 2017).

Research has, however, shown that it is not just brand pressure that promotes supply chain transformation but actually the culture of the supplier, their collaborative networks, the 
competitive landscape (for both brands and suppliers), and the degree of innovativeness in the textile manufacturing sector (Oeleze, 2017; Kim and Zorola, 2018). What is emergent is that suppliers feel that third party auditors want to find something wrong, or that when change is required they do not have the support of their brand partners to make actual changes (Huq et al., 2016). As such, many suppliers feel excluded in sustainability discussions, and face pressures and overlapping requirements from multiple different brand partners (Kim and Zorola, 2018). The authors, therefore, suggest that further research is needed to understand SF practices from a supplier perspective, in different cultural contexts, and how these practices could be expanded across the industry (Caniato et al., 2012; Köksal et al., 2017; Oelze, 2017). Further, few studies incorporate social welfare in their assessment of supply chain sustainability, despite this being a key focus of SF literature to date (Köksal et al., 2017). Those that do are largely underpinned by the application of Fair Trade principles (Goworek, 2011; Dissanayake et al., 2017), with little exploration of other issues of societal interest in the supply chain. Just one study focuses on animal welfare (Molderez and De Landtsheer, 2015) and another on consumer perceptions of leather alternatives (Jung et al., 2016). Considering recent brands Gucci and Michael Kors' commitments to cease fur sourcing and the popularity of fur-free brand Stella McCartney, further insight is needed into the impact of these contextual changes. While de Brito et al. (2008) call for a holistic approach to SF supply chain research, research needs to move beyond solving environmental issues in the supply chain to consider issues of social responsibility and animal welfare; clear gaps for future research (Ni et al., 2017; Köksal et al., 2017).

\section{Social Retail Marketing}

The primary question for social retail marketing (SRM) papers is: how can SF be 
mainstreamed by using traditional retail marketing methods? Some say make it 'trendy' (Beard, 2008; Haug and Busch, 2016; Blanchet 2017), while others question if this is the best approach (Winge, 2008). SRM focuses on the actions of the retailers, promoting the idea that SF is achievable through business as usual practices. The key aspects of SRM research fall into four areas: branding, communications, marketing materials, and barriers to brand adoption of SF.

First, although important, the advice on SF branding is, at best, conflicted. On the one hand, consumer brand schemas are incredibly important in influencing how consumers perceive the fit between sustainability and the brand (Phau and Ong, 2007; Dabija, 2018; Lee et al., 2012; Kim and Hall, 2015). On the other hand, consumers may be more open to SF by fast fashion brands than previously conceptualised (Hill and Lee, 2015). It follows that different segments need to be approached using different marketing methods to speak to heterogeneous consumer needs (Kim et al., 2013; Bhaduri and Ha-Brookshire, 2015; Lee et al., 2015; Di Benedetto, 2017; Dabija, 2018). Despite stories of the impending climate disaster and the ill-treatment of garment workers, many consumers do not consider sustainability when shopping for clothing (Harris et al., 2016). The key question for SF brands is thus, how to attract the uninterested consumer?

The SF literature offers a variety of suggestions in relation to this conundrum, from promoting fashionability (Beard, 2008), positioning SF as a social norm (Kim et al., 2012), as well as emphasising hedonic benefits (Visser et al., 2015) or luxury brand experiences for SF (Karaosman et al., 2017; Han et al., 2017a; Amatulli et al., 2017; see Athwal et al., 2019 for review on sustainable luxury). Brands can also utilise celebrity endorsement (Kang and Choi, 2016; Blanchet, 2017), and invest in creating an inspiring narrative around the brand (Jang et al., 2012; Blanchet, 2017) or SF itself (Blanchet, 2018; Evans and Peirson-Smith, 2018). However, if these strategies fail to truly educate consumers about SF, consumption patterns are repeated and the DSP 
is further strengthened. For dedicated SF consumers, Kim et al. (2012) suggest that marketing claims need to be more specific about the sustainability of the product rather than resorting to discussion of superficial attributes, such as donations to a cause (Phau and Ong, 2007). Interestingly, anti-consumption advertisements by SF brands have been found to lower purchase intention but not necessarily influence consumers' attitude toward buying the product (Hwang et al., 2016). While SF makes consumers think twice, it still results in patronage of the brand (Hwang et al., 2016). More analysis of different messages, (un)intended consequences, and longitudinal studies of the effectiveness of different techniques would be useful in developing branding strategies fit for a sustainable future.

Secondly, research into communication channels reveals the importance of retailers as facilitators of SF consumption and behaviours (see James and Montgomery, 2017a). Both offline and online channels are important for SF retailing (Han et al., 2017b). Physical locations enable consumers to experience SF; challenging their preconceived notions of what SF is and create positive attitudes towards it (Han et al., 2017a; Di Benedetto, 2017; Overdiek, 2018). Yet, social media is identified as the most-used channel to reach consumers (Han et al., 2017b) and is an important platform for communicating norms and fostering brand loyalty in consumers (de Lenne and Vandenbosch, 2017; Kang and Kim, 2017; Strähle and Graff, 2017). Promoting SF on social media has been found to increase purchase intention, positive attitudes, and self-efficacy (de Lenne and Vandenbosch, 2017). Across all of these channels, brands are encouraged to be transparent and 'open' with customers (Beard, 2008; Henninger et al., 2015; James and Montgomery, 2017c) although the opaque nature of SF as a concept makes the scope of overclaiming a major area of concern. 
Da Giau et al.'s (2016) matrix of brands' commitment to, and disclosure of, SF practices, illustrates this challenge. Brands range from 'low disclosure' companies, very committed to SF but who do not advertise it, to those that are, 'not at all committed' but overemphasising the minimal actions that they have adopted. The ideal location in the matrix is to be a company highly committed to SF and able to communicate it effectively, but this quadrant lacks case examples from the extant literature, in particular regarding what efficacy in communications looks like for highly committed SF brands. With successful SF brands like Stella McCartney, People Tree, and Reformation, it would be useful to know what types of messaging and communication are useful for different channels in fostering more SF behaviours.

Thirdly, the majority of research related to marketing material has focussed around the use of 'hang tags' that educate consumers at the point of sale (Thomas, 2008; Moon et al., 2015; Blanchet, 2017, Ma et al., 2017). However, research has found that these channels are rarely understood, with many consumers unaware of the purpose they serve and why they should care (Sonnenberg et al., 2014; Henninger, 2015; Hwang et al., 2015). It has been argued that having information about SF practices on clothing tags is better at generating attention around SF at the point of purchase (Hyllegard et al., 2014). It is however important that labels should be clear and accurate to avoid confusion and greenwashing (Thomas, 2008; Ma et al., 2017; Evans and PeirsonSmith, 2018), as few consumers can truly discern between different terms and accreditations (Hwang et al., 2015). Digital technologies - such as applications that reval the source of an item - have also been suggested to provide people with more detailed and engaging information (Hyllegard et al., 2012; Strähle and Sfameni, 2017). However, methods for developing sustainable behavioural habits at the point of purchase remains an area that is understudied to date.

Finally, dealing first with the barriers to SF adoption, the SF movement has ebbed and 
flowed throughout the years, making some sceptical of its 'stickiness' (Winge, 2008). Although there are many strategies SF brands can implement, they also face a variety of barriers which have been well explored in the literature. SF brands face the same demands as traditional brands (Beard, 2008), however, they have the additional task of educating consumers about what SF is and why they should pay more for it (Harris et al., 2016). Small SF brands face barriers such as a lack of capital for certification and materials (Moon et al., 2015), as well as uncertainty about the appropriateness of existing certifications (Henninger, 2015). As a result of barriers on both sides, profit margins are slim (Beard, 2008; Moon et al., 2015). These issues illustrate why branding is pivotal for the success of SF brands (D'Souza, 2015). In sum, SRM studies blend psychological cues and other retail marketing methods used by traditional retailers, but with a different goal in mind; to help consumers switch from fast fashion to SF. However, SF brands must be wary of acting too much like their non-SF counterparts; this balance is yet to be seriously acknowledged in the SF literature (Winge, 2008; Wilber and Parsicha, 2016). SF retailers, therefore, should challenge themselves to be truly different by taking a holistic view of SF that includes the personal and collective mental well-being of consumers (see also Mick et al., 2011) and respect for producers.

\section{Consumer Behaviour}

A large proportion of the consumer behaviour literature evaluates SF on a micro-level to explore consumer perceptions of SF products and concepts. This section explores these consumer characteristics, as well as drivers and barriers of SF in the context of consumer markets.

Focussing first on the characteristics of consumers, a number of studies have found several drivers of SF consumption. It is argued that self-identified sustainable consumers are becoming 
tired of mindless consumption and desire freedom from the monotony of trends and pressures to consume (Bly et al., 2015; Armstrong et al., 2016b). Some consumers are even beginning to avoid fast fashion entirely for reasons including poor product quality, the desire to support local brands, and the lack of creativity and originality in clothing choices (Kim et al., 2013). The desire to express oneself through cultivating personal style and generally being 'different' from others is a recurring theme in the literature (Gam, 2011; Kim et al., 2013; Han and Chung, 2014; Bly et al., 2015; Cho et al., 2015; Lundblad and Davies, 2015). Moreover, recent work suggests that consumers are becoming more aware of issues in the fashion industry and a desire to 'vote' with their dollars (Ertekin and Atik, 2015; Moon et al., 2015).

The notion of consumer voting is frequently espoused by the media as an easy solution to SF (Wicker, 2017). However, preliminary research on consumer attitudes, values, and perceptions found little evidence that knowledge of ethical issues influences SF consumption (Joergens, 2006; Moore, 2019). Later, consumer attitudes towards the environment were found to be more influential on purchase intention of SF, rather than attitudes toward SF products specifically (Chan and Wong, 2012). In Cowan and Kinley's (2014) study, previous purchases of SF and attitudes towards purchasing SF were found to be the most influential on purchase intention (Cowan and Kinley, 2014). However, in opposition to the dominant research in the supply chain area, the consumption literature repeatedly finds that individuals do not consider the environment in relation to clothing consumption (Joy et al., 2012). The conflicting results illustrate uncertainty about which consumer characteristics, if any, are the most important under which circumstances. However, Table 6 illustrates various values and attitudes that have been found to influence purchase intention of SF.

[Insert Table 6 around here] 
Focussing on consumer drivers, social norms and social pressures are repeatedly found as drivers of SF consumption in consumer psychology studies (Kang et al., 2013; Cowan and Kinley, 2014; Kim et al., 2016; Harris et al., 2016). However, Kang et al. (2013) note social pressure and knowledge of social norms only work on the non-converted because SF consumers are already convinced of the legitimacy of SF issues. Moreover, although social pressures (Kang et al., 2013; Cowan and Kinley, 2014; Ciasullo et al., 2017) and 'saving face' (Wei and Jung, 2017) have been found to significantly influence SF consumption, Sadachar et al.'s (2016) found interpersonal influence did not. Parallels can be drawn here with other types of consumers. Ochoa (2010) explored the relationship between organic food and organic clothes consumption. Interestingly, they found no direct relationship between organic food consumption and willingness to pay for organic clothing (Ochoa, 2010). Similarly, Ritch's (2015) and Nilssen et al.'s (2019) study found the link between the slow food movement and slow fashion consumption is a tenuous one, as people struggle to translate the benefits of slow or organic food into fashion. This emphasises the uniqueness of the SF context. The role clothes play in people's lives, and the complexity of sustainability claims being made, distinguish SF from the typical commodity product categories which dominate extant sustainable consumption research (McDonagh and Prothero, 2014). This suggests a need to move away from the application of extant nudge theories on enhancing sustainable consumption, to a unique set of theory building tools around SF consumption behaviours, built from the fashion consumption (not sustainable consumption) literature.

Finally, numerous barriers to SF consumption have been identified in the literature (Harris et al., 2016). A lack of accessibility and convenience prevents consumers from being able to easily buy or experience SF (Ritch and Schröder, 2012; Han et al., 2017a; Harris et al., 2016; Crane, 
2016; Lai et al., 2017). Perry and Chung (2016) suggest that consumers may not have the time, capacity, or desire to invest extra energy into finding SF. The lack of visibility discourages consumers, often promoting misconceptions about SF as being premium and exclusive (Henninger et al., 2016; Han et al., 2017a). As most SF brands are sold online, there are interesting questions around equality and access to sustainable goods for those with limited access to such platforms or with limited time to seek them out. The SF aesthetic is also often perceived as being unfashionable by mainstream consumers (Joergens, 2006; Gam, 2011; Hill and Lee, 2012; Joy et al., 2012; Cherny-Scanlon, 2016; Pookulangara and Shephard, 2013; Carey and Cervellon, 2014; Harris et al., 2016; Lai et al., 2017). Paradoxically, the less fashionable an item is, the more sustainable consumers believe it to be (Wagner et al., 2018), but so far the question of how to change such preconceptions remains unanswered. Further scepticism surrounds the quality of SF (Wong and Taylor, 2001; Harris et al., 2016; Jung et al., 2016; Kong and Ko, 2017). Yet, Lundblad and Davies (2015) found existing customers of SF brands viewed the product's attributes (including quality) very highly. SF studies illustrate that cultural differences and and the idea of style varies across the world (Joergens, 2006; Carey and Cervellon, 2014; Achabou and Dekhili, 2015; Kong and Ko, 2017) and likely even within countries, suggesting that SF might be more attractive to some demographics and markets (e.g. Scandinavian countries) than others.

As mentioned, SF is largely perceived to be a premium product (Gam, 2011; Pookulangara and Shephard, 2013; Ertekin and Atik, 2015; Moon et al., 2015; Crane, 2016; Henninger et al., 2016; Harris et al., 2016; Lai et al., 2017; McLaren and Goworek, 2017). While some studies have found that people are willing to pay more for SF (Tama et al., 2017; Ciasullo et al., 2017), sustainability is often seen as an additional benefit to clothing rather than an integral aspect (Magnuson et al., 2017). Many consumers find it difficult to justify higher prices (Ritch and 
Schröder, 2012) and although second-hand fashion is often posited as an alternative for buying new SF clothing, for many consumers the idea of buying second-hand is unattractive (Goworek et al., 2013; Tama et al., 2017), shameful, and may affect self-esteem (Chipambwa et al., 2016). In sum, due to these barriers, consumers feel a variety of tensions between their values, desires, commitments, and resources (Joergens, 2006; Jägel et al., 2012; Ritch and Schröder, 2012; Bly et al., 2015; Henninger et al., 2016). Perhaps more important are the reasons why people feel this way. More research into issues of class, race, gender, and power would be useful to understand what cultural aspects need to be addressed in encouraging SF, rather than focussing solely on individual practices.

This begs the question, where does society go from here? For example, if consumers believe SF is inaccessible, what retail channels could change that (Overdiek, 2018)? Or, if consumers think SF is ugly, then maybe more cross-disciplinary work with designers should be the aim (Goworek et al., 2016)? There is also a level of insensitivity that comes with discussing the attitude-behaviour gap (Hiller, 2010), as such scholarship ignores more systematic issues as to how people actually use clothing (Woodward, 2015), why many feel that they have to have the latest fashion, or why can they not afford to purchase SF. Exploring why these issues exist on a societal level seems to be more productive than blaming consumers for the inaction of brands and governments to address more macro-social barriers (Kennedy, 2016) to SF consumption beyond the dominant micro focus.

Having discussed the pragmatic approach to SF, our attention now turns to the more radical change paradigm.

Sustainable Fashion: A Radical View on Production and Consumption 
The radical change literature focuses on novel ways to create value in personal lives and business structures. The analysis reveals that there are four clusters in the radical change approach: sustainable practices, interventions, future leaders, and sustainable business models (Figure 3 ). Each will now be discussed in turn. The literature in quadrant 3 demonstrates a shift from encouraging people to 'buy better' to encouraging them 'not to buy at all' or to engage with alternative forms of consumption. The papers in quadrant 4 examine innovative ways of structuring a SF business for sustainability (Bocken, 2017). These are considered radical changes departing from the DSP around fashion consumption.

\section{Consumer Practices and Communities}

Consumer practices and communities illustrate the growth of what Fletcher (2010) terms a 'slow fashion' culture. Papers within this cluster explore how consumers are changing their fashion-oriented behaviours and practices for a more sustainable future. Further, they investigate communities of practice that evolve from such activities, which have developed subcultures aside from the mainstream fashion system. This is an underdeveloped research area as the SF conversation tends to focus on how mainstream fashion products and consumption can be made more sustainable (Cervellon and Wernerfelt, 2012).

Focussing first on communities, findings suggest that communities are especially important in SF research; SF pioneers (Bly et al., 2015) and consumer communities educate, advise, and teach each other, providing tips and tricks to implementing SF behaviours and avoiding unsustainable practices (Cervellon and Wernerfelt, 2012; Shen et al., 2014). As SF is still considered a niche, communities are a place where alternative practices are accepted and negotiated collectively. Reiley and Delong (2015) found that vintage style communities act as 
trendsetters and often encourage aspiring fashionistas to adopt SF practices. This insider perspective is useful for understanding the importance of context as well as the transition that takes place when implementing SF behaviours. Other studies focus on specific practices amongst consumers, such as avoiding fast fashion (Kim, 2013), relationship formation between wearers and designers (Clarke and Holt, 2015), clothes swapping (Rathinamoorthy et al., 2017), second-hand and vintage shopping (Cevellon et al., 2012; Cassidy and Bennett, 2012; Xu et al., 2014; Reiley and Delong, 2015; Ryding et al., 2017), and clothing disposal behaviours (Sung and Kincade, 2010; Goworek et al., 2013; Yee et al., 2016). However, this is still a limited field with few studies providing generalizable insights.

The balance between bringing consumerism into SF consumption and promoting anticonsumption is a delicate one (Balsiger, 2014). This tension is evident in the literature as much of it still focuses on the consumption of SF products and positions anti-consumption in a different sphere of behaviour. These papers look at what is motivating people to pursue SF and what barriers they face in doing so. Despite their best intentions, pioneers realise that there are trade-offs in their choices. First, they acknowledge that the most sustainable consumption is to not consume at all (Balsiger, 2014), but as pioneers still need to wear clothes, they try to achieve this need in the most sustainable way available. Sceptical of fast fashion brands creating SF lines, accusations of profitdriven motivations and greenwashing draw pioneers away from the mainstream market (Bly et al., 2015), and to some extent, from the ethical fashion market as well, because even clothing made from organic and/or recycled materials are viewed with caution (Goworek et al., 2012). To overcome these barriers, shopping second-hand, making clothing, and reducing consumption are solutions implemented to overcome financial barriers and moral convictions (Bly et al., 2015). Further, although they are environmentally conscious, SF pioneers still desire to be stylish 
(Lundblad and Davies, 2015). This tension is mediated by distinguishing "style" (Cho et al., 2015), which is typified by its uniqueness, from "fashion", which relates to the following trends.

SF consumption and communities have become an alternative means of identity construction (Clarke and Holt, 2016). Here, SF is not just about saving the world, but also saving the self (Lundblad and Davies, 2015; Bly et al., 2015; Clarke and Holt, 2016). Many participants in Armstrong et al.'s (2016b) study felt liberated from the pressure of having to constantly consume to reinvent their identities, and freer to pursue self-expression, pleasure, and selfimprovement goals. This desire and use of SF for self-expression and pleasure shows that not all pioneers will be ecocentric but seek to meet other goals such as creativity and uniqueness (Lundblad and Davies, 2015, Bly et al., 2015, Lang et al., 2016; Clarke and Holt, 2016). Interestingly, for some pioneers, SF has shifted from a lifestyle choice to a business opportunity. The idea of a 'prosumer' in fashion is emerging with consumers who are also producers, participating in activities such as DIY (Hirscher et al., 2018) and co-creation (Strähle and Grünewald, 2017). The integration of these prosumers into the sustainable business model landscape is a particularly fruitful area for future research, alongside the impact thought leaders in this space could have in driving a cultural shift. These additional goals run perpendicular to environmental concerns, painting a very different portrait of the idealised SF pioneer. Although the literature often points to these individuals as exemplars of SF, research is lacking into how effective these practices are, and how different members of society can more broadly scale and facilitate these lifestyles for the masses.

\section{Social Marketing Interventions}

Social marketing intervention papers explore lifestyle and behaviour changes. Because of their radical nature, it is unsurprising that there are few papers in this field. There are two core 
modes of study in this field: Longitudinal reflective studies and one-off intervention studies.

Focussing first on the reflective studies, these tend to introduce participants to SF principles and then challenge them to implement behavioural change, such as abstaining from clothing consumption (Armstrong et al., 2016b), refraining from doing laundry (Jack, 2013), and employing creativity to form personal style (Ruppert-Stroescu et al. 2015; Hirscher et al., 2018). Several data collection techniques are employed in this stream of work, for example, participants are invited to implement new practices, write diaries (Goworek et al., 2012), blog posts (RuppertStroescu et al., 2015; Armstrong et al., 2016b) and participate in interviews to encourage reflexivity. Goworek et al.'s (2012) study, for instance, encouraged participants to do home tasks and workshops; reporting behaviour change in some of the respondents. The research found that fashion practices are formed from habits, suggesting that a consumer can unintentionally engage in environmentally friendly and non-environmentally friendly behaviours. A commonly found issue is that people simply do not know what to do with their old clothes and believe that the government should be taking a larger role in making clothes recycling more straightforward (Goworek et al., 2013; Ekström and Salomonson, 2014). This passes the responsibility for an individual's waste onto a third party and doesn't solve the problem of over-consumption in the first instance. Jack's (2013) study revealed that although habits are important, much of the way we interact with clothing and laundering is shaped by cultural influences, suggesting that for practices to change, the DSP must change first. Yet, how this can be done practically sits at the crux of the problem for all sustainability-related work.

Unlike longitudinal studies, 'one-off' studies act as a litmus test of society's ability to perform SF behaviours. Lapolla and Sanders (2015) hosted a one-off workshop to inspire participants to use their clothes for longer through upcycling and redesigning. The workshop 
revealed that for this commonly suggested behaviour to come to life, many need more skills to actualise their designs (Lapolla and Sanders, 2015). Participants in this, and similar studies, are reported as coming away inspired to think about what they could do with the clothes they owned; and were encouraged to see beyond their limitations and imagine what they could achieve (Janigo and Wu 2015; Lapolla and Sanders, 2015). Most studies do not follow up with the participants post study, however, Hirscher et al., (2018) did follow up with their participants a year later and found some still used the clothing they made in their workshop, suggesting a bond was formed between the maker and the item.

Creativity in redesign and repurposing is frequently identified as helping people to keep their clothes for longer, but individuals need to be equipped with the skills to apply their creativity in this way (Ruppert-Stroescu et al. 2015; Janigo and Wu, 2015; Lapolla and Sanders, 2015; Hirscher et al., 2018). Even lacking simple skills such as sewing (removed from UK curriculum alongside home economics in the 2000s), are leaving many people unskilled in even the basic capabilities needed to apply their creativity. This highlights a societal capability gap in achieving the focus on mending and building lasting relationships with clothing in Western contexts (Fletcher, 2008). Research on re-skilling society to take care of, and mend, clothing would be useful to turn these one-off studies into practices people can implement.

Other stakeholders such as non-governmental organisations (NGOs), retailers, and governments also influence the DSP, and so social marketing intervention research falls across the consumption-production continuum. Ekström and Salomonson (2014) and Balsiger (2014) explore how production-side stakeholders can form networks to facilitate SF behaviours in consumers, while Grappi et al. (2017) explore the effects of a campaign against unethical behaviour by fashion brands. Ekström and Salomonson (2014) employ actor-network theory to brainstorm collaborative 
solutions to the SF crisis such as educating consumers, making clothing recycling easier, and creating comprehensive accreditation labels. Grappi et al. (2017) found campaign interventions shaming brands are particularly useful in segments where consumers are unlikely to justify a brand's unethical behaviour. They further suggest a brand's non-compliance with consumer campaigns negatively influences consumers' attitudes towards the brands. Such campaigns can encourage consumers to be more critical of brands, thus reducing future purchase intention and encouraging more sustainable consumption (Grappi et al., 2017). This has implications for other NGOs and brands. On the NGO side, campaigns requiring action may be an effective tool to drive change, while brands should take these campaigns more seriously or face backlash from their customers. As evidenced by the variety of papers in this area, SF fashion is more than just a consumer behaviour issue, but there is a lack of research exploring how to mobilise diverse stakeholders in facilitating behavioural change (Winge, 2008; Ekström and Salomonson, 2014; Ertekin and Atik, 2015). Future research should explore if and how these key stakeholders attempt to radically influence SF behaviours and what results they achieve.

\section{Future Leaders}

A relatively small cluster and a latecomer in the evolution of SF research, future leaders research takes the view that for society to change, everyone, including academia, needs to play a part. However, Armstrong and LeHew (2014) found integrating SF issues into curricula is difficult as educators often face a lack of support and community in conducting such modules. Further, sustainability education in business schools questions the purpose of business education, highlighting unique tensions between educating students to do business better and how to effectively design and market products. 
A primary aim of higher education is to prepare students to be employable (Williams, 2016). However, the job market for fashion and management students has changed significantly and as brands grapple with the demands for increased sustainability, a new set of skills will be required (Williams, 2016). Educators realise to equip these students for grand social challenges and the future, they must also equip them with sustainability knowledge and related analytical skills sets. These papers target future leaders, management and fashion students, to increase their knowledge and awareness of SF issues in society, with the hope they will inspire and implement change (Landgren and Pasricha, 2011; Armstrong et al., 2016b) and to develop sustainable behaviours in their fashion (non) consumption (Connell and Kozar, 2012; Ruppert-Stroescu et al. 2015; Armstrong et al., 2016b).

Typically, underpinning these pedagogical studies, are subjective epistemologies (Landgren and Pasricha, 2011), using theories centred on experiential learning and reflexivity, encouraging students to be active participants in their learning (Armstrong and LeHew, 2014). Educators are in a unique position to study students since they engage with them on a weekly basis over several weeks, enabling researchers to observe change over time. Due to this unique vantage point, the most common methodology is to develop modules that act as a social experiment (Armstrong and LeHew, 2014). Many experiments are designed with the independent variable being information exposure and the dependent variable as reported behaviour change (Connell and Kozar, 2012; Baytar and Ashdown, 2014). Others take a more disruptive approach and require students to actively participate in changing and documenting their behaviour changes (Goworek et al., 2012; Ruppert-Stroescu et al., 2015; Armstrong et al., 2016b). Armstrong et al. (2016b), for instance, invited students to participate in a 'fashion detox' where they abstained from fashion consumption for 10 weeks while writing blog posts to document their experience. As a result, 
students felt less temptation to shop for clothes as they learned to better differentiate 'needs' from 'wants', and to exercise self-control. However, many students felt compelled to buy something at the end of the experiment, illustrating rebound effects. Again, focussing only on the consumer may yield unexpected results. Future research could explore these effects further and how they might be reduced when implementing interventions.

Overall, the results have been varied as each experiment has been designed differently. Storytelling through videos (Baytar and Ashdown, 2014), incorporating SF concepts into modules (Armstrong and LeHew, 2014), and designing modules around SF (Connell and Kozar, 2011; Williams, 2016) might help increase SF-related knowledge in students. While in terms of behaviour change, dance therapy (Thornquist, 2018) and encouraging creativity and abstinence may be ways to reduce consumption (Ruppert-Stroescu et al. 2015; Armstrong et al., 2016b). There are a lot of opportunities to engage with students as they are not only future leaders but also high consumers of fashion. Moreover, although these studies were conducted over a series of weeks, whether students' consumer behaviour has actually been changed or if they have brought these ideas into the workplace has yet to be confirmed (Connell and Kozar, 2012).

\section{Sustainable Fashion Business Models}

A variety of SF business models have been identified and discussed within the literature from collaborative fashion consumption (CFC) models including renting, sharing, and swapping (Pederson and Netter, 2015; Armstrong et al., 2015; Armstrong et al., 2016; Becker-Leifhold and Iran, 2018; Johnson et al., 2016; Strähle and Erhardt, 2017; Todeschini et al., 2017, Pal, 2017; Iran and Schrader, 2017; Zamani et al., 2017; Iran, 2018) to second-hand retailing (McColl, 2013; Chan et al., 2015; Strähle and Höhn, 2017; Strähle and Klatt, 2017; Pal, 2017), and upcycled goods 
(Janigo and Wu, 2015; Todeschini et al., 2017; Pal, 2017). Beyond business models, other studies analyse the practices of micro-organisations and their owner-managers (Leslie et al., 2014; Lewis and Pringle, 2015; Gurova and Morozova, 2016; Henninger et al., 2016; DiVito and Bohnsack, 2017). These papers illustrate the tensions and trade-offs that innovative business models face but also highlight the complexity of what constitutes SF in an environment where there is no clear minimum bar to be reached in making SF claims. For example, innovative businesses face the issue of scale, such as being able to offer consistent styles and quality, which is a barrier to most business models (Cassidy and Han, 2013; Pal and Gander, 2018). Micro-organisations are already under financial pressure to keep prices competitive and invest in higher quality materials, however with limited resources they cannot do everything on their own (DiVito and Bohnsack, 2017). What this means for $\mathrm{SF}$ is that the traditional model of scaling up businesses may not be appropriate to achieve the aims sustainability requires. This requires institutional investors to also reconsider what metrics may be appropriate for evaluating SF business models. As of yet, this area is underresearched in the SF management literature.

Much of the qualitative and mixed methods research, that dominates this field of research, focuses on consumer perceptions of SF business models. Although useful to know how consumers perceive these business models, it is imperative to analyse the potential rebound, environmental and social effects of these business models and evaluate their suitability for a sustainable future. Very few papers have addressed this issue (e.g. Hu, 2016; Iran and Schrader, 2017, Zamani et al., 2017; Strähle and Erhardt, 2017). Becker-Leifhold and Iran (2018) discuss difficulties preventing collaborative consumption from becoming mainstream while Pal and Gander (2018) discuss the merits and disadvantages of various SF business models. Fashion rental could reduce the environmental impact of fashion consumption however it is dependent on adoption (Armstrong et 
al., 2015; Zamani et al., 2017; Becker-Leifhold and Iran, 2018). Similarly, it is unclear whether fashion rental (such as circular economy business models like MUD Jeans, where you lease jeans at a cost comparable to buying a pair of Levis), are genuinely more sustainable or simply a means of increasing business profitability as with other servitization business models (Neely, 2008).

Overall, work exploring SF business models is very limited, with few exemplars on which to build a conceptual model of how to make the fashion sector function from a sustainability perspective.

\section{Discussion and Research Agenda}

Having presented the review, SF materialises as a varied and complex field of study. Despite the identification of 465 papers directly addressing SF, it is still a field in its infancy with large gaps in understanding. Table 7 summarises the key areas for future research identified above and this section now synthesises the findings, drawing out key conclusions and an agenda for future research. Moreover, while the difference between pragmatic and radical change perspectives on how to deliver more SF practices has been highlighted, the authors advocate for a combination of both approaches to make meaningful ecological change to how fashion is produced and consumed. In drawing the different clusters together, six overarching themes are identified: appealing to a wider demographic, changing shopping habits, influencing production, shaping social practices, upskilling the future, and developing a fit-for-purpose labelling scheme.

[Insert Table 7 around here]

\section{Appealing To a Wider Demographic}


It can be surmised from the review that it is imperative to avoid incremental repetition of sustainable consumption theory into this new SF context. The qualitative and particularly radical approach highlights the need for new SF theory building, beyond what is already known about sustainable behaviours in commodity markets. There is a unique fashion literature (Fletcher; Niinimäki, 2010) which provides a wealth of insight into why consumers buy the products they do, which can vary wildly from the rationale for commodity-based products (Davies et al., 2012). Yet this research is rarely linked to the SF consumption research explored at present. Those that do link these fields such as Hwang et al. (2016), Beard (2008), and Visser et al. (2015) find linking sustainability to a benefit for the consumer is by far the most powerful approach to engaging consumers in sustainable consumption practice. Further, most studies on SF consumer behaviour utilise convenience sampling amongst female university students, however, this seems like a missed opportunity to engage with other demographics considering an ageing population in many Western countries, a rising middle class in the developing world, and a booming menswear market. College students are at a very specific life stage, therefore applying learnings from their context to the wider population should be done with caution. Future research should consider sampling individuals of various genders, life stages, ethnicities, and incomes (see Ritch and Schröder, 2012; D’Souza et al., 2015; Kozar and Connell, 2015; Henninger and Singh, 2017; Liang and Xu, 2017, 2017; Dabija, 2018). Interdisciplinary insight may also offer a deeper understanding of how SF may become normalised (Shaw et al., 2016).

\section{Changing Shopping Habits}

There is still a clear need to address the main purpose of the SF literature: how to change habits towards greater sustainability throughout the marketplace. This goal resonates not only at 
the consumer level (Armstrong et al., 2016b; Goworek et al., 2012; Lapolla and Sanders, 2015), but also throughout the demand chain literature (Beard, 2008). However, research into habitforming around SF is limited. In the consumer space an over-reliance on outdated, and often refuted theories of consumer decision-making (Bagozzi, 1975; Belk, 1988), limits the development of the field. As aforementioned, consumption in areas such as organic and slow food does not translate to fashion (Ochoa, 2010; Ritch, 2015). A focus on cognitive decision-making similarly does not tackle consumption as a habit but as a cognitive process. Theories more applicable to fashion consumption need to be developed. Where research has built from a fashion theory perspective (Niinimäki, 2010; Thornquist, 2018), markedly different results emerge than the imposition of cognitive behavioural theory. To know how consumer habits change, new theories of consumption need to be developed. For instance, research could investigate social innovations that are enabling new ways for people to engage with SF behaviours. Interventions, longitudinal studies, and innovative research designs may be useful in exploring this uncharted territory where the externalities of habit change are largely unknown.

\section{Influencing Production}

The lack of insight into consumer habit-forming is mirrored in a lack of research into organisational habits. Research into organisational decision-making is a particularly fruitful field for creating change because organisations have so much more institutional power and reach than individuals. Looking at Fairtrade as an example, it is countries where the retailers and major brands made the switch with their product lines (Ireland, Switzerland, and the UK) that dominate the national Fairtrade sales per capita, not where consumer pull was strongest (Doherty et al., 2013). 
This highlights a significant gap in the literature regarding how to influence change in major brands, manufacturers, and retailers.

Here the paper strikes a healthy accord with DesJardins (2016, p.133): "It would be difficult to imagine a better challenge for entrepreneurs and business leaders than to actualize the business opportunities created by a sustainable economy". The overemphasis on the consumer perspectives of sustainable business models, as opposed to research exploring what a SF business model could practically be, is a notable gap in the literature. Similarly, the limited research exploring the avenues for growth of micro-organisations and how they could better collaborate/partner with larger organisations is a potentially limiting factor. Beyond Molderez and De Landtsheer (2015), Adam (2018), and Adam et al. (2018); there is little consideration of how a major change can occur in the marketing system. This is an important issue because as shown in the consumer behaviour section, there is still little consumer demand for SF (Joy et al., 2012). Rapid change is therefore likely to come from either micro-organisational mainstreaming, or mainstream players evolving in the face of consumer scepticism (Wong and Taylor, 2001; Harris et al., 2016; Jung et al., 2016). How these organisations can be influenced to make change is a vital gap that needs addressing.

\section{Shaping Social Practices}

So far this paper has mostly responded to the marketization of more sustainable alternatives. However, also within this institutional space is the need for research exploring how to shape social practices and support sustainable clothing, pro-sumption, laundering, reuse, and ultimately disposal. Indeed, most existing SF consumers acknowledge that not consuming "new" is the most sustainable option (Balsiger, 2014; Bly et al., 2015). Yet, how society can address the 
lack of structural and cultural support for alternatives will be vital to the expansion of these niche fields and communities of practice. Although research into these areas is emerging, current findings repeatedly show that structural barriers such as a lack of reuse opportunities, limited choice in second-hand purchasing options, a lack of recycling availability and limited alternatives to laundering, constrain the ability to engage in SF behaviours. Combined with a lack of skills, education, and information around SF alternatives, these constraints limit the freedom of pioneers to express their sustainable identities and lifestyles. Insight into how this can be addressed through local, organisational, national, and international movements or policies is severely lacking. Case examples of where some of the barriers to alternative lifestyles have been addressed would be a good starting point, but a broader debate of how to provide people with the requisite knowledge, skills, and societal support to live more sustainably remains one of the biggest unanswered questions of the present time.

\section{Upskilling Future Leaders}

There are many opportunities to encourage interventions outside of the retail context. One emerging area is the role of education. The radical change research suggests that educators should empower students as agents of change and provide them with the skills necessary for understanding sustainability (Pasricha and Kadolph, 2009; Armstrong and LeHew, 2014; Williams, 2016). Many consumers perceive a lack of institutional support structures for recycling (Goworek et al., 2013; Ekström and Salomonson, 2014), and many people believe that they lack the craft skills and creativity to undertake more radical approaches to SF such as reuse, repurposing or creating individual style (Lapolla and Sanders, 2015; Janigo and Wu, 2015). In many countries, these skills have become less of a focus in recent decades, leaving today's graduates far 
less capable of living sustainably than previous generations. In lieu of being able to change the education system, the provision of places and spaces for development in these areas may fall on the third-sector of civil society, but studies investigating the role that could be played by thirdsector organisations is presently lacking.

\section{Developing a Fit-For-Purpose Labelling Scheme}

A method commonly adopted in fashion, as well as many other industries, is to rely on labelling as a means of sustainability communication (Thomas, 2008; Hwang et al., 2015; Henninger, 2015). Problems with labelling from a cost and consumer scepticism perspective have been aforementioned (Henninger, 2015), however without a mechanism for labelling to support or evidence product claims, there is an inherent barrier to change. A variety of characteristics underpin SF, yet a sufficient labelling scheme has yet to be adopted in theory and practice (Moon et al., 2015; Henninger et al., 2016). This is largely due to what the authors' term the 'SF imbroglio.' Whist many organisations such as Not my Style, Good on You, and the Sustainable Apparel Coalition have developed rating schemes and organisations such as Positive Luxury have created labelling schemes, very few of these schemes have broken into the mainstream. The Positive Luxury 'Butterfly label' is making great headway, however, the obvious limitation is that it only considers the niche area of luxury products. Nonetheless, recent developments by Stora Enso (a Finnish-Swedish forestry, pulp, packaging and renewable materials company) of an 'ECO RFID' tag offering a cloud-based track and trace solution for retailers and manufacturers offer hope in the development of such complex data management solutions (Roberti, 2018).

Academics have also attempted to alleviate this gap by developing matrices and continua to organise SF practices in the context of labelling. Henninger et al. (2016) created a matrix of 
possible SF activities that a brand could undertake while Pederson and Anderson (2015) developed a continuum of where a brand was positioned on a variety of dimensions. However, as discussed above, consumers tend to be sceptical of labels (Bly et al., 2015) and lack the requisite knowledge to apply them in their decision making (Sonnenberg et al., 2014; Henninger 2015; Hwang et al., 2015; McLaren and Goworek, 2017). Further empirical research is needed to explore how the diversity of what constitutes SF can be converted into something easily digestible for both retailers and consumers; similar to the energy ratings in electronic goods, or nutritional "traffic lights" on pre-packaged food items.

\section{Conclusion}

This review aimed to answer the question, "what do we know about SF in management and where do we go from here?" This review paper finds that pragmatic change is facilitated within the existing SF market (Doherty et al., 2013), whereas radical change adopts a more nuanced view of what SF might become through innovative business models, empowering changemakers, and better understanding SF consumer lifestyles. Although academic research into SF has shown a dip from 2018, pragmatic interest is advancing more than more radical research, especially research into future leaders and social marketing interventions. However, while this paper advocates that both approaches are necessary to translate SF ideals into a mainstream practice, there remain to be significant gaps in knowledge, particularly in habit formation both individually and corporately. Much SF research is undertaken in silos, however by crossing disciplinary lines, exciting new ideas may be introduced into the field. This review of SF contributes to the literature by mapping out what we know and how we know it as well as outlining ways that as researchers and practitioners can co-create a SF future. 
In terms of practitioner and policy implications, we can see several areas in which the powerful institutions in the fashion market - retailers and brand owners - can provide a more fertile environment for SF. The first is around consumer communication. As discussed above hangtags have very questionable benefits, due to the complexity of information and consumer scepticism of claims. The textile industry coalescing around a consistent approach to sustainability communications would be a powerful approach to simplifying the point of sale decisions. A consistent labelling approach (such as the $\mathrm{ABC}$ ratings on electrical goods, or traffic lights on food) would help both educate and inform consumers, however as evidenced in the literature social media and digital channels are the most likely touchpoint for many fashion consumers. Utilisation of these channels to provide coherency and transparency in sustainability communications appears key in both engaging committed SF consumers and educating sceptical or non-consumers.

Further, in these communications, it is vital to identify benefits to the self, including the personal and collective mental well-being of consumers (Mick et al., 2011) and respect for producers. Existing SF consumers see benefits to self in the consumption of more sustainable clothing, but at present these are unclear to non-consumers. A focus for branded manufacturers on style, quality and branding appear essential in being successful in this sphere, so linking sustainability to hedonic benefits appears key. However, retailers and branded manufacturers should also work on building supplier networks and promoting supplier innovation in tackling sustainability challenges. Too much focus has been placed on enforcement and auditing rather than galvanising the collective brain of the supply network in addressing core negative issues in the fashion sector. Creating networks (e.g. in the coffee supply network, Davies and Doherty, 2019) for suppliers to share best practice, develop innovations and collectively solve problems, could be a key mechanism to evolve the whole supply chain leading to a universally more sustainable 
textiles sector. Finally, the role of governments, NGOs, education and the third-sector need to be better integrated around policies to change the DSP. Collective action by all stakeholders to reshape our education system, remove barriers to sustainable consumption and facilitate sustainable business models is needed for lasting change. This requires multiple parties to come together to address key areas of concern. No dominant body yet exists encompassing all of these stakeholders, where transparency and free flow of information can develop, but we have a duty to ourselves and our environment to create such a platform.

\section{Acknowledgements}

The authors declare there are no conflicts of interest in this study. 


\section{References in Text}

Adam, M. (2018), "The role of human resource management (HRM) for the implementation of sustainable product-service systems (PSS)-An analysis of fashion retailers", Sustainability, Vol. 10 No.7, pp. 2518.

Adam, M., Strähle, J., \& Freise, M. (2018), "Dynamic capabilities of early-stage firms: Exploring the business of renting fashion", Journal of Small Business Strategy, Vol. 28 No. 2, pp. 49-67.

Achabou, M. A. and Dekhili, S. (2015), "Constraints and Drivers of Growth in the Ethical Fashion Sector: The Case of France”, in Choi, T.M. and Cheng, T.C.E. (Ed.), Sustainable Fashion Supply Chain Management: From Sourcing to Retailing, Springer, Cham, pp. 167-181.

Amatulli, C., Costabile, M., De Angelis, M. and Guido, G. (2017), "Luxury, Sustainability, and "Made In"', in Amatulli, C., De Angelis, M., Costabile, M. and Guido, G. (Ed.), Sustainable Luxury Brands, Palgrave Macmillan, London, pp. 35-96.

Armstrong, C. and LeHew, M. (2014), "Barriers and Mechanisms for the Integration of Sustainability in Textile and Apparel Education: Stories from the Front Line", Fashion Practice: The Journal of Design, Creative Process \& the Fashion, Vol. 6 No. 1, pp. 59-86.

Armstrong, C. M., Connell, K. Y. H., Lang, C., Ruppert-Stroescu, M. and LeHew, M. L. A. (2016b), "Educating for Sustainable Fashion: Using Clothing Acquisition Abstinence to Explore Sustainable Consumption and Life Beyond Growth", Journal of Consumer Policy, Vol. 39 No. 4, pp. 417-439.

Armstrong, C. M., Niinimäki, K., Kujala, S., Karell, E. and Lang, C. (2015), "Sustainable product-service systems for clothing: Exploring consumer perceptions of consumption alternatives in Finland", Journal of Cleaner Production., Vol. 97, pp. 30-39.

Armstrong, C. M., Niinimäki, K., Lang, C., Kujala, S., Niinimäki, K., Lang, C. and Kujala, S. (2016), “A Use-Oriented Clothing Economy? Preliminary Affirmation for Sustainable Clothing Consumption Alternatives", Sustainable Development, Vol. 24 No. 1, pp. 18-31.

Bagozzi, R. P. (1975), "Marketing as Exchange”, Journal of Marketing, Vol. 39 No. 4, pp. 32-39.

Balsiger, P. (2014), "Between shaming corporations and promoting alternatives: The politics of an "ethical shopping map"', Journal of Consumer Culture, Vol. 14 No. 2, pp. 218-235.

Barnett-Page, E. and Thomas, J. (2009), "Methods for the synthesis of qualitative research: a critical review”, BMC Medical Research Methodology, Vol. 9 No. 1, pp. 59.

Baytar, F. and Ashdown, S. P. (2014), "Using video as a storytelling medium to influence textile and clothing students environmental knowledge and attitudes", International Journal of Fashion Design, Technology and Education, Vol. 7 No. 1, pp. 31-41.

Beard, N. D. (2008), "The Branding of Ethical Fashion and the Consumer: A Luxury Niche or Massmarket Reality?", Fashion Theory, Vol. 12 No. 4, pp. 447-467.

Becker-Leifhold, C. and Iran, S. (2018), "Collaborative fashion consumption - drivers, barriers and future pathways", Journal of Fashion Marketing and Management, Vol. 22 No.2, pp. 189-208.

Belk, R. (1988), "Possessions and the Extended Self”, Journal of Consumer Research, Vol. 15 No. 2, pp. 139-168.

Bhaduri, G. and Ha-Brookshire, J. (2015), "Gender differences in information processing and transparency: cases of apparel brands' social responsibility claims", The Journal of Product and Brand Management, Vol. 24 No. 5, pp. 504-517.

Black, S. and Anderson, S. (2010), "Making Sustainability Fashionable: Profile of the Danish Fashion Company Noir", Fashion Practice the Journal of Design Creative Process \& The Fashion Industry, Vol. 2 No.1, pp. 121-128. 
Blanchet, V. (2017), "“We make markets": The role of the Ethical Fashion Show in categorising the ethical fashion", Recherche et Applications en Marketing (English Edition), Vol. 32 No. 2, pp. 2645.

Blanchet, V. (2018), "Performing market categories through visual inscriptions: The case of ethical fashion", Organization, Vol. 25 No. 3, pp. 374-400.

Bly, S., Gwozdz, W. and Reisch, L. (2015), "Exit from the high street: an exploratory study of sustainable fashion consumption pioneers", International Journal of Consumer Studies, Vol. 39 No. 2, pp.125-135.

Bocken, N. (2017), "Business-led sustainable consumption initiatives: impacts and lessons learned", Journal of Management Development, Vol. 36 No.1, pp. 81-96.

Bouzon, M. \& Govindan, K. (2015), "Reverse Logistics as a Sustainable Supply Chain Practice for the Fashion Industry: An Analysis of Drivers and the Brazilian Case", in Choi, T.-M. and Cheng, T.C.E. (Ed.), Sustainable Fashion Supply Chain Management. Springer, Cham, pp. 85-104.

Burrell, G. and Morgan, G. (1979), Sociological paradigms and organisational analysis. Heinemann, London.

Caniato, F., Caridi, M., Crippa, L. and Moretto, A. (2012), "Environmental sustainability in fashion supply chains: An exploratory case based research", International Journal of Production Economics, Vol. 135 No. 2, pp. 659-670.

Carey, L. and Cervellon, M.-C. (2014), "Ethical fashion dimensions: pictorial and auditory depictions through three cultural perspectives", Journal of Fashion Marketing and Management: An International Journal, Vol. 18 No. 4, pp. 483-506.

Cassidy, T. and Bennett, H. (2012), "The Rise of Vintage Fashion and the Vintage Consumer", Fashion Practice, Vol. 4 No.2, pp.239-261.

Cervellon, M.-C., Carey, L. and Harms, T. (2012), "Something old, something used", International Journal of Retail \& Distribution Management, Vol. 40 No. 12, pp. 956-974.

Cervellon, M.-C. M. and Wernerfelt, A.-S. (2012), "Knowledge sharing among green fashion communities online: Lessons for the sustainable supply chain”, Journal of Fashion Marketing \& Management, Vol. 16 No. 2, pp. 176-192.

Chan, H.-L., Choi, T.-M., and Lok, J. C.-Y. (2015), "Mass Market Second-Hand Clothing Retail Operations in Hong Kong: A Case Study", in Choi TM. and Cheng T. (Ed.), Sustainable Fashion Supply Chain Management, Springer, Cham, pp. 155-165.

Chan, T.-Y and Wong, C. W. Y. (2012), "The consumption side of sustainable fashion supply chain', Journal of Fashion Marketing and Management, Vol. 16 No. 2, pp. 193-215.

Cherny-Scanlon, X. (2016), "Putting Glam into Green: A Case for Sustainable Luxury Fashion", in Dhiman, S. and Marques, J. (Ed.), Spirituality and Sustainability. Springer, Cham, pp. 183-197.

Chipambwa, W., Sithole, L., and Chisosa, D. F. (2016), "Consumer perceptions towards second-hand undergarments in Zimbabwe: a case of Harare urban dwellers", International Journal of Fashion Design, Technology and Education, Vol. 9 No. 3, pp.176-182.

Cho, E., Gupta, S. and Kim, Y.-K. (2015), "Style consumption: its drivers and role in sustainable apparel consumption", International Journal of Consumer Studies, Vol. 39 No. 6, pp. 661-669.

Ciarapica, F. E., De Sanctis, I., Resta, B., Dotti, S., Gaiardelli, P., Bandinelli, R., Fani, V. and Rinaldi, R. (2017), "Integrating Sustainability in the Fashion System Using Association Rules", in Rinaldi, R. and Bandinelli, R. (Ed.), Business Models and ICT Technologies for the Fashion Supply Chain, Springer, Cham, pp. 239-250. 
Ciasullo, M. V., Maione, G., Torre, C, and Troisi, O. (2017), "What about Sustainability? An Empirical Analysis of Consumers' Purchasing Behavior in Fashion Context”, SUSTAINABILITY, Vol. 9 No. 9, pp.1617.

Cimatti, B., Campana, G. and Carluccio, L. (2017), "Eco Design and Sustainable Manufacturing in Fashion: A Case Study in the Luxury Personal Accessories Industry”, in Seliger, G., Kohl, H. and Oosthuizen, G.A. (Ed.), Procedia Manufacturing, pp. 393-400.

Clark, H. (2008), "SLOW plus FASHION-an Oxymoron-or a Promise for the Future ...?", Fashion Theory, Vol. 12 No. 4, pp. 427-446.

Clarke, J. S. and Holt, R. (2016), "Vivienne Westwood and the Ethics of Consuming Fashion", Journal of Management Inquiry, Vol. 25 No. 2, pp. 199-213.

Common Objective. (2018). "Volume and Consumption: How Much Does The World Buy?", available at: https://www.commonobjective.co/article/volume-and-consumption-how-much-does-theworld-buy (Accessed 25 Jul. 2019).

Connell, K. Y. H. and Kozar, J. M. (2012), "Sustainability knowledge and behaviors of apparel and textile undergraduates", International Journal of Sustainability in Higher Education, Vol. 13 No. 4, pp. 394-407.

Cowan, K. and Kinley, T. (2014), “Green spirit: consumer empathies for green apparel”, International Journal of Consumer Studies, Vol. 38 No. 5, pp. 493-499.

Crane, D. (2016), "The puzzle of the ethical fashion consumer: Implications for the future of the fashion system", International Journal of Fashion Studies, Vol. 3 No. 2, pp. 249-265.

Dory, K. (2018), "Why Fast Fashion Needs to Slow Down", available at: https://www.unenvironment.org/news-and-stories/blog-post/why-fast-fashion-needs-slow-down (accessed 23 January 2019).

D’Souza, C. (2015), "Marketing Challenges for an Eco-fashion Brand: A Case Study", Fashion Theory, Vol. 19 No.1, pp. 67-82.

D’Souza, C., Gilmore, A. J., Hartmann, P., Apaolaza Ibanez, V., Sullivan-Mort, G., Apaolaza Ibáñez, V. and Sullivan-Mort, G. (2015), "Male eco-fashion: a market reality", International Journal of Consumer Studies, Vol. 39 No. 1, pp. 35-42.

Da Giau, A., Macchion, L., Caniato, F., Caridi, M., Danese, P., Rinaldi, R. and Vinelli, A. (2016), "Sustainability practices and web-based communication", Journal of Fashion Marketing and Management, Vol. 20 No. 1, pp. 72-88.

Dabija, D.-C. (2018), "Enhancing green loyalty towards apparel retail stores: A cross-generational analysis on an emerging market", Journal of Open Innovation: Technology, Market, and Complexity, Vol. 4 No. 8, pp. 1-16.

Davies, J. (2014), "The Basic Principles of Production Management", available at: http://www.winman.com/blog/bid/341826/the-basic-principles-of-production-management (accessed 12 May 2018).

Davies, I.A. and Doherty, B., (2019), "Balancing a hybrid business model: The search for equilibrium at Cafédirect." Journal of Business Ethics, Vol. 157, No. 4, pp 1043-1066.

de Brito, M. P., Carbone, V. and Blanquart, C. M. (2008), "Towards a sustainable fashion retail supply chain in Europe: Organisation and performance", International Journal of Production Economics, Vol. 114 No. 2, pp. 534-553.

de Lenne, O. and Vandenbosch, L. (2017), "Media and sustainable apparel buying intention", Journal of Fashion Marketing and Management, Vol. 21 No.4, pp. 483-498.

Denyer, D. and Tranfield, D. (2006), "Using qualitative research synthesis to build an actionable knowledge base". Management Decision, Vol. 44 No. 2, pp. 213-227. 
Denyer, D. and Pilbeam, C. (2013). Doing a literature review in business and management.

DesJardins, J. (2016), "Is it Time to Jump off the Sustainability Bandwagon?", Business Ethics Quarterly, Vol. 26 No.1, pp. 117-135.

Di Benedetto, C. A. (2017), "Corporate social responsibility as an emerging business model in fashion marketing”, Journal of Global Fashion Marketing, Vol. 8 No. 4, pp. 251-265.

Diddi, S. and Niehm, L. S. (2016), "Corporate Social Responsibility in the Retail Apparel Context: Exploring Consumers' Personal and Normative Influences on Patronage Intentions”, Journal of Marketing Channels, Vol. 23 No. 1-2, pp. 60-76.

Diddi, S. and Niehm, L. S. (2017), "Exploring the role of values and norms towards consumers' intentions to patronize retail apparel brands engaged in corporate social responsibility (CSR)", Fashion and Textiles, Vol. 4 No. 5, pp. 1-20.

Dissanayake, D. G. K., Perera, S. and Wanniarachchi, T. (2017), "Sustainable and ethical manufacturing: a case study from handloom industry", Textiles and Clothing Sustainability, Vol. 3 No. 2, pp. 110 .

DiVito, L. and Bohnsack, R. (2017), "Entrepreneurial orientation and its effect on sustainability decision tradeoffs: The case of sustainable fashion firms", Journal of Business Venturing, Vol. 32 No. 5, pp. 569-587.

Doherty, B., Davies, I. and Tranchell, S. (2013), “Where now for Fair Trade?”, Business History, Vol. 55 No. 2, pp. 161-189.

Ellis, J. L., McCracken, V. A. and Skuza, N. (2012), "Insights into willingness to pay for organic cotton apparel", Journal of Fashion Marketing and Management, Vol. 16 No. 3, pp. 290-305.

Ekström, K. M. and Salomonson, N. (2014), "Reuse and Recycling of Clothing and Textiles-A Network Approach", Journal of Macromarketing, Vol. 34 No. 3, pp. 383-399.

Ertekin, Z. O. and Atik, D. (2015), "Sustainable Markets: Motivating Factors, Barriers, and Remedies for Mobilization of Slow Fashion", Journal of Macromarketing, Vol. 35 No. 1, pp. 53-69.

Evans, S. and Peirson-Smith, A. (2018), "The sustainability word challenge", Journal of Fashion Marketing and Management, Vol. 22 No. 2, pp. 252-269.

Fashion United (2018). "Global Fashion Industry Statistics-International Apparel”, available at: https://fashionunited.com/global-fashion-industry-statistics (accessed 23 Jan 2019).

Fletcher, K. (2008), Sustainable Fashion and Textiles: Design Journeys, Routledge, London.

Fletcher, K. (2010), "Slow Fashion: An Invitation for Systems Change", Fashion Practice, Vol. 2 No. 2 , pp. 259-266.

Fulton, K. and Seung-Eun, L. (2013), "Assessing sustainable initiatives of apparel retailers on the internet", Journal of Fashion Marketing and Management, Vol. 17 No. 3, pp. 353-366.

Gam, H. J. (2011),"Are fashion-conscious consumers more likely to adopt eco-friendly clothing?", Journal of Fashion Marketing and Management, Vol. 15 No. 2, pp. 178-193.

Geiger, S. M. and Keller, J. (2017), "Shopping for Clothes and Sensitivity to the Suffering of Others: The Role of Compassion and Values in Sustainable Fashion Consumption", Environment and Behavior, Vol. 50 No. 10, pp. 1119-1144.

Goworek, H. (2011), "Social and environmental sustainability in the clothing industry: a case study of a fair-trade retailer", Social Responsibility Journal, Vol. 7 No. 1, pp. 74-86.

Goworek, H., Fisher, T., Cooper, T., Woodward, S. and Hiller, A. (2012), "The sustainable clothing market: an evaluation of potential strategies for UK retailers", International Journal of Retail and Distribution Management, pp. 935-955.

Goworek, H., Hiller, A., Fisher, T., Cooper, T. and Woodward, S. (2013), “Consumers' attitudes towards sustainable fashion Clothing usage and disposal", in Gardetti, M.A. and Torres, A.L. (Ed.) 
Sustainability in Fashion and Textiles: Values, Design, Production and Consumption, Greenleaf, Sheffield, pp. 376-392.

Goworek, H., Perry, P., and Kent, A. (2016), "The relationship between design and marketing in the fashion industry", Journal of Fashion Marketing and Management, Vol. 20 No. 3.

Grappi, S., Romani, S. and Barbarossa, C. (2017), "Fashion without pollution: How consumers evaluate brands after an NGO campaign aimed at reducing toxic chemicals in the fashion industry", Journal of Cleaner Production, Vol. 149, pp. 1164-1173.

Gurova, O. and Morozova, D. (2016), “A critical approach to sustainable fashion: Practices of clothing designers in the Kallio neighborhood of Helsinki", Journal of Consumer Culture, Vol. 18 No. 3 , pp. 397-413.

Han, J., Seo, Y. and Ko, E. (2017a), "Staging luxury experiences for understanding sustainable fashion consumption: A balance theory application", Journal of Business Research, Vol. 74, pp. 162-167.

Han, S. L.-C., Henninger, C. E., Apeagyei, P. and Tyler, D. (2017b), "Determining Effective Sustainable Fashion Communication Strategies', in Henninger C., Alevizou P., Goworek H. and Ryding D. (Ed.), Sustainability in Fashion, Palgrave Macmillan, Cham, pp. 127-149.

Harris, F., Roby, H. and Dibb, S. (2016), "Sustainable clothing: challenges, barriers and interventions for encouraging more sustainable consumer behaviour", International Journal of Consumer Studies, Vol. 40 No. 3, pp. 309-318.

Haug, A. and Busch, J. (2016), “Towards an Ethical Fashion Framework”, Fashion Theory, Vol. 20 No.3, pp. 317-339.

Henninger, C. E. (2015), "Traceability the New Eco-Label in the Slow-Fashion Industry?-Consumer Perceptions and Micro-Organisations Responses”, SUSTAINABILITY, Vol. 7 No. 5, pp. 60116032.

Henninger, C. E. and Singh, P. (2017), "Ethical Consumption Patterns and the Link to Purchasing Sustainable Fashion", in Henninger C., Alevizou P., Goworek H. and Ryding D. (Ed.), Sustainability in Fashion. Palgrave Macmillan, Cham, pp. 103-126.

Henninger, C. E., Alevizou, P. J. and Oates, C. J. (2016), "What is sustainable fashion?", Journal of Fashion Marketing and Management, Vol. 20 No. 4, pp. 400-416.

Henninger, C.E., Alevizou, P.J., Oates, C.J. and Cheng, R. (2015), "Sustainable Supply Chain Management in the Slow-Fashion Industry", in Choi, T.M. and Cheng, T. (Ed.), Sustainable Fashion Supply Chain Management: From Sourcing to Retailing. Springer, Cham, pp. 129-153.

Hill, J. and Lee, H. (2012), "Young Generation Y consumers' perceptions of sustainability in the apparel industry", Journal of Fashion Marketing and Management, Vol. 16 No. 4, pp. 477-491.

Hill, J. and Lee, H.-H. (2015), "Sustainable brand extensions of fast fashion retailers", Journal of Fashion Marketing and Management, Vol. 19 No. 2, pp. 205-222.

Hiller, A. J. (2010), "Challenges in researching consumer ethics: a methodological experiment", Qualitative Market Research, Vol. 13 No. 3, pp. 236-252.

Hirscher, A.-L., Niinimäki, K. and Joyner Armstrong, C. M. (2018), "Social manufacturing in the fashion sector: New value creation through alternative design strategies?", Journal of Cleaner Production, Vol. 172, pp. 4544-4554.

Holbrook, M. (1987), What is Consumer Research?, Journal of Consumer Research, Vol. 14 No. 1, pp.128-132.

Hu, Z.-H. (2016), "Distribution, Transshipment, and Sustainable Logistics for Fashion Products", in Choi, T.M. (Ed.), Analytical Modeling Research in Fashion Business, Springer, Singapore, pp. 155-196. 
Huq, F. A., Chowdhury, I. N., and Klassen, R. D. (2016), "Social management capabilities of multinational buying firms and their emerging market suppliers: An exploratory study of the clothing industry", Journal of Operations Management, Vol. 46, pp.19-37.

Hwang, C. G., Lee, Y.-A. and Diddi, S. (2015), “Generation Y's moral obligation and purchase intentions for organic, fair-trade, and recycled apparel products", International Journal of Fashion Design, Technology and Education, Vol. 8 No. 2, pp. 97-107.

Hwang, C., Lee, Y., Diddi, S. and Karpova, E. (2016), “"Don't buy this jacket”". Journal of Fashion Marketing and Management, Vol. 20 No. 4, pp. 435-452.

Hyllegard, K. H., Yan, R.-N., Ogle, J. P. and Lee, K.-H. (2012), “Socially Responsible Labeling: The Impact of Hang Tags on Consumers' Attitudes and Patronage Intentions Toward an Apparel Brand", Clothing and Textiles Research Journal, Vol. 30 No. 1, pp. 51-66.

Hyllegard, K., Paff Ogle, J. and Yan, R.-N. (2014), “College students' responses to prosocial marketing claims on apparel hang tags", Journal of Fashion Marketing and Management, Vol. 18 No. 3, pp. 269-283.

Iran, S. (2018), "Sustainable Fashion: From Production to Alternative Consumption", in Jastram S. and Schneider A.M. (Ed.), Sustainable Fashion, Springer, Cham, pp. 139-159.

Iran, S. and Schrader, U. (2017), "Collaborative fashion consumption and its environmental effects", Journal of Fashion Marketing and Management, Vol. 21 No. 4, pp. 468-482.

Jack, T. (2013), "Laundry routine and resource consumption in Australia", International Journal of Consumer Studies, Vol. 37 No. 6, pp.666-674.

James A.M., Montgomery B. (2017a), "The Role of the Retailer in Socially Responsible Fashion Purchasing", in Muthu S. (Ed.), Textiles and Clothing Sustainability, Springer, Singapore, pp. 140.

James, A. M. and Montgomery, B. (2017c), "Engaging the fashion consumer in a transparent business model", International Journal of Fashion Design, Technology and Education, Vol. 10 No. 3, pp. 287-299.

Jang, J., Ko, E., Chun, E. and Lee, E. (2012), “A Study of a Social Content Model for Sustainable Development in the Fast Fashion Industry", Journal of Global Fashion Marketing, Vol. 3 No. 2, pp. 61-70.

Janigo, K. A. and Wu, J. (2015), "Collaborative Redesign of Used Clothes as a Sustainable Fashion Solution and Potential Business Opportunity", Fashion Practice, Vol. 7 No. 1, pp. 75-98.

Jastram, S. and Schneider, A.-M. (2015), "Sustainable fashion governance at the example of the partnership for sustainable textiles", uwf, Vol. 23 No. 4, pp. 205-212.

Joergens, C. (2006), "Ethical fashion: myth or future trend?", Journal of Fashion Marketing and Management, Vol. 10 No. 3, pp. 360-371.

Johnson, K. K. P., Lee, M., Choi, D., Mun, J. M. and Yoo, N. (2013), “Trends in research addressing fashion and social responsibility”, Journal of Global Fashion Marketing, Vol. 4 No. 3, pp. 145157.

Johnson, K. K. P., Mun, J. M. and Chae, Y. (2016), "Antecedents to internet use to collaboratively consume apparel”, Journal of Fashion Marketing and Management, Vol. 20 No. 4, pp. 370-382.

Joy, A. and Peña, C. (2017), "Sustainability and the Fashion Industry: Conceptualizing Nature and Traceability", in Henninger C., Alevizou P., Goworek H., and Ryding D. (Ed.), Sustainability in Fashion, Palgrave Macmillan, Cham, pp. 31-54.

Joy, A., Sherry, J., Venkatesh, A., Wang, J. and Chan, R. (2012), "Fast Fashion, Sustainability, and the Ethical Appeal of Luxury Brands”, Fashion Theory, Vol. 16 No. 3, pp. 273-295. 
Jung, H. J., Kim, H. and Oh, K. W. (2016), "Green Leather for Ethical Consumers in China and Korea: Facilitating Ethical Consumption with Value-Belief-Attitude Logic", Journal of Business Ethics, Vol. 135 No. 3, pp. 483-502.

Jung, S. and Jin, B. (2014), "A theoretical investigation of slow fashion: sustainable future of the apparel industry”, International Journal of Consumer Studies, Vol. 38 No. 5, pp. 510-519.

Jung, S. and Jin, B. (2015), "Time to be Slow? Slow Movement in the Apparel Business", in Kubacki K. (Ed.), Ideas in Marketing: Finding the New and Polishing the Old. Developments in Marketing Science: Proceedings of the Academy of Marketing Science, Springer, Cham, pp. 565-568.

Jung, S. and Jin, B. (2016), "From quantity to quality: understanding slow fashion consumers for sustainability and consumer education", International Journal of Consumer Studies, Vol. 40 No. 4, pp. 410-421.

Kang, J. and Choi, W. (2016), "Endorsed Sustainable Products: The Role of Celebrity Ethicality and Brand Ethicality", Clothing and Textiles Research Journal, Vol. 34 No. 4, pp.303-319.

Kang, J., Liu, C. and Kim, S.-H. (2013), "Environmentally sustainable textile and apparel consumption: the role of consumer knowledge, perceived consumer effectiveness and perceived personal relevance", International Journal of Consumer Studies, Vol. 37 No. 4, pp. 442-452.

Kang, J.-Y. M. and Kim, J. (2017), "Online customer relationship marketing tactics through social media and perceived customer retention orientation of the green retailer", Journal of Fashion Marketing and Management, Vol. 21 No.3, pp. 298-316.

Karaosman, H., Morales-Alonso, G. and Brun, A. (2016), "From a Systematic Literature Review to a Classification Framework: Sustainability Integration in Fashion Operations", SUSTAINABILITY, Vol. 9 No. 1, pp.1-19.

Karaosman, H., Morales-Alonso, G. and Brun, A. (2017), "Strike a pose: Luxury for sustainability", in Gardetti, M. (Ed.), Sustainable Management of Luxury, Springer, Singapore, pp. 145-162.

Kennedy, A. M. (2016), "Macro-social Marketing”, Journal of Macromarketing, Vol. 36 No. 3, pp. 354365.

Kim, H., Choo, H. J., Yoon, N., Jung Choo, H. and Yoon, N. (2013), "The motivational drivers of fast fashion avoidance", Journal of Fashion Marketing and Management, Vol. 17 No. 2, pp. 243-260.

Kim, H., Kim, J., Oh, K. W. and Jung, H. J. (2016), “Adoption of Eco-Friendly Faux Leather”, Clothing and Textiles Research Journal, Vol. 34 No. 4, pp. 239-256.

Kim, H., Lee, E.-J. and Hur, W.-M. (2012), “The Normative Social Influence on Eco-Friendly Consumer Behavior: The Moderating Effect of Environmental Marketing Claims", Clothing and Textiles Research Journal, Vol. 30 No.1, pp. 4-18.

Kim, H.-S. and Hall, M. L. (2015), "Green Brand Strategies in the Fashion Industry: Leveraging Connections of the Consumer, Brand, and Environmental Sustainability", in Choi, T.M. and Cheng T., Sustainable Fashion Supply Chain Management, Springer, Cham, pp. 31-45.

Kim, J. and Zorola, M. (2018), "Sustainable Innovation in the Apparel Supply Chain: Case Study on TAL Apparel Limited", in Chow PS., Chiu CH., C. Y. Yip A. and K. Y. Tang A. (Ed.), Contemporary Case Studies on Fashion Production, Marketing and Operations, Springer, Singapore, pp. 183197.

Kogg, B. (2003), "Greening a Cotton-textile Supply Chain; A Case Study of the Transition towards Organic Production without a Powerful Focal Company", Greener Management International, No. 43, pp. 53-64..

Köksal, D., Strähle, J., Müller, M. and Freise, M. (2017), "Social Sustainable Supply Chain Management in the Textile and Apparel Industry-A Literature Review", SUSTAINABILITY, Vol. 9 No. 1, pp. 100 . 
Kong, H. M. and Ko, E. (2017), "Why do consumers choose sustainable fashion? A cross-cultural study of South Korean, Chinese, and Japanese consumers", Journal of Global Fashion Marketing, Vol. 8 No. 3, pp. 220-234.

Kong, H. M., Ko, E., Chae, H. and Mattila, P. (2016), 'Understanding fashion consumers' attitude and behavioral intention toward sustainable fashion products: Focus on sustainable knowledge sources and knowledge types", Journal of Global Fashion Marketing, Vol. 7 No. 2, pp. 103-119.

Kozar, J. M. and Connell, K. Y. H. (2015), "Sustainability in the Apparel and Textiles Industry: A Conceptual Paper Addressing Previous Findings and Areas of Future Research", in Robinson, Jr. L. (Ed.), Marketing Dynamism \& Sustainability: Things Change, Things Stay the Same..., Springer, Cham, pp. 229-237.

Kozlowski, A., Bardecki, M. and Searcy, C. (2012), "Environmental Impacts in the Fashion Industry: A Life-cycle and Stakeholder Framework", Journal of Corporate Citizenship, No. 45, pp. 17-36.

Lai, Z., Henninger, C. E. and Alevizou, P. J. (2017), “An Exploration of Consumers' Perceptions Towards Sustainable Fashion - A Qualitative Study in the UK”, in Henninger C., Alevizou P., Goworek H., and Ryding D. (Ed.), Sustainability in Fashion. Palgrave Macmillan, Cham, pp. 81-101.

Landgren, T. M. and Pasricha, A. (2011), "Transforming the fashion and apparel curriculum to incorporate sustainability", International Journal of Fashion Design, Technology and Education, Vol. 4 No. 3, pp. 187-196.

Lang, C., Armstrong, C. M. and Liu, C. (2016), "Creativity and sustainable apparel retail models: does consumers' tendency for creative choice counter-conformity matter in sustainability?", Fashion Textiles, Vol. 3 No. 24, pp. 1-15.

Lapolla, K. and Sanders, E. B.-N. (2015), "Using Cocreation to Engage Everyday Creativity in Reusing and Repairing Apparel", Clothing and Textiles Research Journal, Vol. 33 No.3, pp. 183-198.

Lee, K. E. (2017), "Environmental Sustainability in the Textile Industry”, in Muthu S. (Ed.), Sustainability in the Textile Industry, Springer, Singapore, pp. 17-55.

Lee, N., Choi, Y. J., Youn, C. and Lee, Y. (2012), "Does Green Fashion Retailing Make Consumers More Eco-friendly?: The Influence of Green Fashion Products and Campaigns on Green Consciousness and Behavior", Clothing and Textiles Research Journal, Vol. 30 No. 1, pp. 67-82.

Lee, S. (2011), “Consumers' Value, Environmental Consciousness, and Willingness to Pay more toward Green-Apparel Products", Journal of Global Fashion Marketing, Vol. 2 No. 3, pp. 161-169.

Leslie, D., Brail, S. and Hunt, M. (2014), "Crafting an Antidote to Fast Fashion: The Case of Toronto's Independent Fashion Design Sector", Growth and Change, Vol. 45 No. 2, pp. 222-239.

Lewis, T. L. and Pringle, A. (2015), "Local Buttons: Sustainable Fashion and Social Entrepreneurship in Haiti”, Nka Journal of Contemporary African Art, No. 37, pp. 114-125.

Lundblad, L. and Davies, I. A. (2016), "The values and motivations behind sustainable fashion consumption”, Journal of Consumer Behaviour, Vol. 15 No. 2, pp. 149-162.

Ma, Y. J., Gam, H. J. and Banning, J. (2017), "Perceived ease of use and usefulness of sustainability labels on apparel products: application of the technology acceptance model", Fashion and Textiles, Vol. 4 No. 3, pp. 1-20.

Ma, Y. J., Lee, H.-H. and Goerlitz, K. (2016), "Transparency of Global Apparel Supply Chains: Quantitative Analysis of Corporate Disclosures", Corporate Social Responsibility and Environmental Management, Vol. 23 No. 5, pp. 308-318.

Magnuson, B., Reimers, V. and Chao, F. (2017), "Re-visiting an old topic with a new approach: the case of ethical clothing", Journal of Fashion Marketing and Management, Vol. 21 No. 3, pp. 400-418..

Manchiraju, S. and Sadachar, A. (2014), "Personal values and ethical fashion consumption", Journal of Fashion Marketing and Management, Vol. 18 No. 3, pp. 357-374. 
McColl, J., Canning, C., McBride, L., Nobbs, K. and Shearer, L. (2013), "It's Vintage Darling! An exploration of vintage fashion retailing”, Journal of the Textile Institute, Vol. 104 No. 2, pp. 140150.

McDonagh, P., Dobscha, S., and Prothero, A. (2011), "Sustainable Consumption and Production: Challenges for Transformative Consumer Research", in Mick, D., Pettigrew, S., Pechmann, C. and Ozanne, J. (Ed.), Transformative Consumer Research for Personal and Collective Well Being: Reviews and Frontiers Routledge, Florida, pp. 267-282

McDonagh, P. and Prothero, A. (2014), "Sustainability marketing research: past, present and future", Journal of Marketing Management, Vol. 30 No.11-12, pp. 1186-1219.

McDonagh, P. and Prothero, A. (2015), "Unpacking corporate sustainability: sustainable communication, waste and the 3Rs in network society", in Ekström, K.M. (Ed.), Waste Management and Sustainable Consumption: Reflections on consumer waste, pp. 166-183.

McLaren, A. and Goworek, H. (2017), "Investigating the Relationship Between Consumer Attitudes and Sustainable Fashion Product Development", in Henninger C., Alevizou P., Goworek H., and Ryding D, Sustainability in Fashion, Palgrave Macmillan, Cham, pp. 171-192.

McNeill, L. and Moore, R. (2015), "Sustainable fashion consumption and the fast fashion conundrum: fashionable consumers and attitudes to sustainability in clothing choice", International Journal of Consumer Studies, Vol. 39 No. 3, pp. 212-222.

Mick, D., Pettigrew, S., Pechmann, C., and Ozanne, J. (2011), Transformative consumer research for personal and collective well-being, Routledge, New York.

Moher, D., Liberati, A., Tetzlaff, J., Altman, D.G. and The PRISMA Group (2009), "Preferred Reporting Items for Systematic Reviews and Meta-Analyses: The PRISMA Statement", PLoS Med, Vol. 6 No. 7, pp. 1-6.

Molderez, I. and De Landtsheer, P. (2015), "Sustainable Fashion and Animal Welfare: Non-Violence as a Business Strategy", in Bouckaert, L. and Chatterji, M., Business, Ethics and Peace, pp. 351-370.

Moon, K. K.-L., Lai, C. S.-Y., Lam, E. Y.-N., and Chang, J. M. T. T. (2015), "Popularization of sustainable fashion: barriers and solutions", Journal of The Textile Institute, Vol. 106 No. 9, pp. 939-952.

Moore, K. (2019), "Report Shows Customers Want Responsible Fashion, But Don't Want To Pay For It. What Should Brands Do?", available at: https://www.forbes.com/sites/kaleighmoore/2019/06/05/report-shows-customers-wantresponsible-fashion-but-dont-want-to-pay-for-it/\#416a60001782 (Accessed 26 Jul. 2019).

Nagurney, A. and Yu, M. (2012), "Sustainable fashion supply chain management under oligopolistic competition and brand differentiation", International Journal of Production Economics, Vol. 135 No. 2, pp. 532-540.

Nam, C., Dong, H. and Lee, Y.-A. (2017), “Factors influencing consumers' purchase intention of green sportswear", Fashion and Textiles, Vol. 4 No. 2, pp. 1-17.

Neely, A. (2008), "Exploring the financial consequences of the servitization of manufacturing." Operations Management Research, Vol. 1, No. 2, pp. 103-118.

Ng, N. K.-Y., Chow, P.-S. and Choi, T.-M. (2015), "Impacts of Social Media Mediated Electronic Words of Mouth on Young Consumers' Disposal of Fashion Apparel: A Review and Proposed Model", in Choi TM. and Cheng T. (Ed.), Sustainable Fashion Supply Chain Management, Springer, Cham, pp. 47-58.

Niinimäki, K. (2010), “Eco-clothing, consumer identity and ideology”, Sustainable Development, Vol. 18 No. 3, pp. 150-162. 
Nilssen, R., Bick, G., \& Abratt, R. (2019), "Comparing the relative importance of sustainability as a consumer purchase criterion of food and clothing in the retail sector", Journal of Brand Management, Vol. 26 No. 1, pp. 71-83.

Niu, B., Chen, L. and Zhang, J. (2017), "Punishing or subsidizing? Regulation analysis of sustainable fashion procurement strategies", Transportation Research Part E: Logistics and Transportation Review, Vol. 107, pp. 81-96.

Oelze, N. (2017), "Sustainable Supply Chain Management Implementation-Enablers and Barriers in the Textile Industry", SUSTAINABILITY, Vol. 9 No. 8, pp. 1435.

Ochoa, L.M.C. (2010), “Will 'Eco-Fashion' Take Off? A Survey of Potential Customers of Organic Cotton Clothes in London", AD-MINISTER, Vol. 16, pp. 115-132.

Overdiek, A. (2018), "Opportunities for slow fashion retail in temporary stores", Journal of Fashion Marketing and Management, Vol. 22 No. 1, pp. 67-81.

Pal, R. (2017), "Sustainable Design and Business Models in Textile and Fashion Industry", in Muthu S. (Ed.), Sustainability in the Textile Industry, Springer, Singapore, pp. 109-138.

Pal, R. and Gander, J. (2018), "Modelling environmental value: An examination of sustainable business models within the fashion industry", Journal of Cleaner Production, Vol. 184, pp. 251-263.

Paras, M. and Curteza, A. (2018), "Revisiting upcycling phenomena: a concept in clothing industry", Research Journal of Textile and Apparel, Vol. 22 No. 1, pp. 46-58.

Pasricha, A. and Kadolph, S. J. (2009), "Millennial generation and fashion education: a discussion on agents of change", International Journal of Fashion Design, Technology and Education, Vol. 2 No. 2-3, pp. 119-126.

Pedersen, E. R. G. and Andersen, K. R. (2015), "Sustainability innovators and anchor draggers: a global expert study on sustainable fashion", Journal of Fashion Marketing And Management, Vol. 19 No. 3, pp. 315-327.

Pedersen, E. R. G. and Netter, S. (2015), "Collaborative consumption: business model opportunities and barriers for fashion libraries", Journal of Fashion Marketing and Management, Vol. 19 No. 3, pp. $258-273$.

Perry, A. and Chung, T. (2016), "Understand attitude-behavior gaps and benefit-behavior connections in Eco-Apparel”, Journal of Fashion Marketing and Management, Vol. 20 No. 1, pp. 105-119.

Perry, P., Kauric, A. G. and Novak, I. (2014), "Corporate social responsibility in fashion supply chains: people and knowledge in the Croation footwear industry (Case study)", in Economic and Social Development: Book of Proceedings, Varazdin Development and Entrepreneurship Agency, Varazdin, pp. 275-282.

Pessôa, C., Araújo, K., and Arruda, A. (2015), "Discussing Consumption and Sustainability in Clothing Production: A Case Study of a Company in Recife/BR”, Procedia Manufacturing, Vol. 3, pp. 6175-6182.

Phau, I. and Ong, D. (2007), "An investigation of the effects of environmental claims in promotional messages for clothing brands", Marketing Intelligence \& Planning, Vol. 25 No. 7, pp. 772-788.

Pookulangara, S. d and Shephard, A. (2013), "Slow fashion movement: Understanding consumer perceptions an exploratory study", Journal of Retailing and Consumer Services, Vol. 20 No. 2, pp. 200-206.

Prothero, A., McDonagh, P. and Dobscha, S. (2010), "Is Green the New Black? Reflections on a Green Commodity Discourse", Journal of Macromarketing, Vol. 30 No. 2, pp.147-159. 
Pui-Yan Ho, H. and Choi, T. (2012), “A Five-R analysis for sustainable fashion supply chain management in Hong Kong: a case analysis", Journal of Fashion Marketing and Management, Vol. 16 No. 2, pp. 161-175.

Rathinamoorthy, R., Surjit, R., and Karthik, T. (2017), “Clothing Swap: Gateway to Sustainable Ecofriendly Fashion", in Martínez L., Kharissova O., and Kharisov B. (Ed.), Handbook of Ecomaterials. Springer, Cham, pp. 1-24.

Razzaq, A., Ansari, N. Y., Razzaq, Z., and Awan, H. M. (2018), “The Impact of Fashion Involvement and Pro-Environmental Attitude on Sustainable Clothing Consumption: The Moderating Role of Islamic Religiosity", Vol. 8 No. 2, pp. 1-17.

Reiley, K. and DeLong, M. (2011), "A Consumer Vision for Sustainable Fashion Practice”, Fashion Practice, Vol. 3 No. 1, pp. 63-84.

Reimers, V., Magnuson, B. and Chao, F. (2016), "The academic conceptualisation of ethical clothing Could it account for the attitude behaviour gap?", Journal of Fashion Marketing and Management, Vol. 20 No. 4, pp. 383-399.

Resta, B., Dotti, S., Pinto, R., and Gaiardelli, P. (2013), “A Decision Making Process for Sustainability in the Textile Sector", in Prabhu V., Taisch M., and Kiritsis D. (Ed.), Advances in Production Management Systems. Sustainable Production and Service Supply Chains. APMS 2013. IFIP Advances in Information and Communication Technology, Springer, Berlin, pp. 418-425.

Ritch, E. L. (2015), "Consumers interpreting sustainability: moving beyond food to fashion", International Journal of Retail \& Distribution Management, Vol. 43 No. 12, pp. 1162-1181.

Ritch, E. L. and Schröder, M. J. (2012), "Accessing and affording sustainability: the experience of fashion consumption within young families”, International Journal of Consumer Studies, Vol. 36 No. 2, pp. 203-210.

Roberti, M. (2018), "The renewable materials company has introduced its ECO RFID sustainable tag technology, along with software and services, to create a complete solution for retailers and industrial manufacturers", available at: https://www.rfidjournal.com/articles/pdf?17987 (accessed 23 November 2018)

Roos, S., Sandin, G., Zamani, B., Peters, G., and Svanström, M. (2017), "Will Clothing Be Sustainable? Clarifying Sustainable Fashion”, in Muthu, S. (Ed.), Textiles and Clothing Sustainability. Textile Science and Clothing Technology, Springer, Singapore, pp. 1-45.

Ruppert-Stroescu, M., LeHew, M. L. A., Connell, K. Y. H. and Armstrong, C. M. (2015), "Creativity and Sustainable Fashion Apparel Consumption: The Fashion Detox", Clothing and Textiles Research Journal, Vol. 33 No. 3, pp. 167-182.

Ryding, D., Wang, M., Fox, C. and Xu, Y. (2017), "A Review of Secondhand Luxury and Vintage Clothing", in Henninger C., Alevizou P., Goworek H. and Ryding D. (Ed.), Sustainability in Fashion, Palgrave Macmillan, Cham, pp. 245-266.

Sadachar, A., Khare, A. and Manchiraju, S. (2016), "The Role of Consumer Susceptibility to Interpersonal Influence in Predicting Green Apparel Consumption Behavior of American Youth", Atlantic Marketing Journal, Vol. 5 No. 1, pp. 1-15.

Scaturro, S. (2008), "Eco-tech Fashion: Rationalizing Technology in Sustainable Fashion", Fashion Theory, Vol. 12 No. 4, pp. 469-488.

Shaw, D., McMaster, R., and Newholm, T. (2016), "Care and Commitment in Ethical Consumption: An Exploration of the "Attitude-Behaviour Gap"', Journal of Business Ethics, Vol. 136 No. 2, pp. 251-265.

Shen, B., Zheng, J.-H., Chow, P.-S., and Chow, K.-Y. (2014), "Perception of fashion sustainability in online community", Journal of The Textile Institute, Vol. 105 No. 9, pp. 971-979. 
Shih W.C. and Agrafiotis K. (2018), "Detoxifying the Supply Chains: Production Networks of Slow Garment Factories in South-Eastern Europe", in Muthu, S. (Ed.), Detox Fashion, Springer, Singapore, pp. 1-27.

Shih, W. C. and Agrafiotis, K. (2016), "The Sustainable Luxury Craft of Bespoke Tailoring and Its' Enduring Competitive Advantage", in Gardetti, M. and Muthu, S. (Ed.), Handbook of Sustainable Luxury Textiles and Fashion, Springer, Singapore, pp. 137-161.

Short, J. (2009), The Art of Writing a Review Article, Journal of Management, Vol. 35 No. 6, pp.13121317.

Sonnenberg, N., Jacobs, B., and Momberg, D. (2014), "The Role of Information Exposure in Female University Students' Evaluation and Selection of Eco-Friendly Apparel in the South African Emerging Economy", Clothing and Textiles Research Journal, Vol. 32 No. 4, pp. 266-281. .

Strähle, J. and Erhardt, C. (2017), "Collaborative Consumption 2.0: An Alternative to Fast Fashion Consumption”, in Strähle, J. (Ed.), Green Fashion Retail, Springer, Singapore, pp. 135-155.

Strähle, J. and Gräff, C. (2017), “The Role of Social Media for a Sustainable Consumption”, in Strähle, J (Ed.), Green Fashion Retail, Springer, Singapore, pp. 225-247.

Strähle, J. and Grünewald, A.-K. (2017), "The Prosumer Concept in Fashion Retail: Potentials and Limitations", in Strähle, J (Ed.), Green Fashion Retail, Springer, Singapore, pp. 95-117.

Strähle, J. and Höhn, M. (2017), "Cross-Industry Learnings: What Fashion Retail Can Learn from the Used-Car Industry”, in Strähle, J (Ed.), Green Fashion Retail, Springer, Singapore, pp. 157-174.

Strähle, J. and Klatt, L. M. (2017), "The Second Hand Market for Fashion Products”, in Strähle, J (Ed.), Green Fashion Retail, Springer, Singapore, pp. 119-134.

Strähle, J. and Müller, V. (2017), "Key Aspects of Sustainability in Fashion Retail”, in Strähle, J (Ed.), Green Fashion Retail, Springer, Singapore, pp. 7-26.

Strähle, J. and Schnaidt, A. (2017), “Case Study: Loop Extension of Filippa K”, in Strähle, J (Ed.), Green Fashion Retail, Springer, Singapore, pp. 199-223.

Strähle, J. and Sfameni, M. C. (2017), "Potentials of a Fashion fTRACE App", in Strähle, J (Ed.), Green Fashion Retail, Springer, Singapore, pp. 249-268.

Su, J., (Tu) Watchravesringkan, K. and Zhou, J. (2018), "Young Consumers' Perceptions of Sustainable Clothing: Empirical Insights from Chinese Post-90s' College Students”, in Xu Y., Chi T., and Su J. (Ed.), Springer, Singapore, pp. 97-117.

Sung, H. W. and Kincade, D. H. (2010), "Typology of Korean Eco-sumers: Based on Clothing Disposal Behaviors", Journal of Global Academy of Marketing Science, Vol. 20 No. 1, pp. 59-69.

Tama, D., Cureklibatir Encan, B., and Ondogan, Z. (2017), "University students' attitude towards clothes in terms of environmental sustainability and slow fashion", Tekstil Ve Konfeksiyon, Vol. 27 No.2, pp. 191-197.

Tey, Y. S., Brindal, M., and Dibba, H. (2018), "Factors influencing willingness to pay for sustainable apparel: A literature review", Journal of Global Fashion Marketing, Vol. 9 No. 2, pp. 129-147.

Thomas, J. and Harden, A. (2008), "Methods for the thematic synthesis of qualitative research in systematic reviews", BMC Medical Research Methodology, Vol. 8 No. 45.

Thomas, S. (2008), "From "Green Blur" to Ecofashion: Fashioning an Eco-lexicon", Fashion Theory, Vol. 12 No. 4, pp. 525-539.

Thompson, A. and Tong, X. (2016), “Factors influencing college students' purchase intention towards Bamboo textile and apparel products”, International Journal of Fashion Design, Technology and Education, Vol. 9 No, 1, pp. 62-70.

Thornquist, C. (2018), "The potential of dance: Reducing fashion consumption through movement therapy", Journal of Cleaner Production, Vol. 183, pp. 824-830. 
Todeschini, B. V., Cortimiglia, M. N., Callegaro-de-Menezes, D., and Ghezzi, A. (2017), "Innovative and sustainable business models in the fashion industry: Entrepreneurial drivers, opportunities, and challenges", Business Horizons, Vol. 60 No.6, pp. 759-770.

Tranfield, D., Denyer, D., and Smart, P. (2003), "Towards a Methodology for Developing EvidenceInformed Management Knowledge by Means of Systematic Review", British Journal of Management, Vol. 14 No. 3, pp. 207-222.

Turker, D. and Altuntas, C. (2014), "Sustainable supply chain management in the fast fashion industry: An analysis of corporate reports", European Management Journal, Vol. 32 No. 5, pp. 837-849.

Vadicherla, T. and Saravanan, D. (2015), "Sustainable Measures Taken by Brands, Retailers, and Manufacturers", in Muthu S. (Ed.), Roadmap to Sustainable Textiles and Clothing, Springer, Singapore, pp. 109-135.

Visser, M., Gattol, V., and Helm, R. Vander (2015), "Communicating Sustainable Shoes to Mainstream Consumers: The Impact of Advertisement Design on Buying Intention”, SUSTAINABILITY, Vol. 7 No. 7, pp. 8420-8436.

Wagner, M., Curteza, A., Chen, Y., Thomassey, S. and Zeng, X. (2018), "Environmentally-Friendly Perception of Fashion Products: A Kansei Study", in Lokman, A., Yamanaka, T., Lévy, P., Chen, K. and Koyama, S. (Ed.), Proceedings of the 7th International Conference on Kansei Engineering and Emotion Research 2018, Springer, Singapore, pp. 369-378.

Wang, L. and Shen, B. (2017), “A Product Line Analysis for Eco-Designed Fashion Products: Evidence from an Outdoor Sportswear Brand", SUSTAINABILITY, Vol. 9 No, 7, pp. 1136.

Wei, X. and Jung, S. (2017), "Understanding Chinese Consumers' Intention to Purchase Sustainable Fashion Products: The Moderating Role of Face-Saving Orientation”, SUSTAINABILITY, Vol. 9 No. 9, pp. 1570.

Wicker, A. (2017), "Conscious consumerism is a lie. Here's a better way to help save the world", available at: https://qz.com/920561/conscious-consumerism-is-a-lie-heres-a-better-way-to-help-save-theworld/ (Accessed 26 Jul. 2019).

Wilber, J. and Pasricha, A. (2017), "Content analysis of web-based narrative for Fair Trade apparel", International Journal of Fashion Design, Technology and Education, Vol. 10 No. 3, pp. 331-342.

Williams, D. (2016), "Transition to Transformation in Fashion Education for Sustainability", in eal Filho W. and Brandli L. (Ed.), Springer, Cham, pp. 217-232.

Winge, T. M. (2008), "“'Green Is the New Black": Celebrity Chic and the "Green" Commodity Fetish", Fashion Theory, Vol. 12 No. 4, pp. 511-523.

Wong, E. and Taylor, G. (2000), ""Practitioner Papers: An investigation of ethical sourcing practices: Levi Strauss \& Co", Journal of Fashion Marketing and Management, Vol. 4 No. 1, pp. 71-79.

Wong, J. and Taylor, G. (2001), "The Market Potential of Environmental Clothing Products in the Hong Kong Retail Industry", Journal of the Textile Institute, Vol. 92 No. 1, pp. 1-18.

Woodward, S. (2015), "Accidentally sustainable? Ethnographic approaches to clothing practices", in Fletcher, K. and Tham, M. (Ed.), Routledge Handbook of Sustainability and Fashion, Routledge, New York, pp. 131-138.

Xu, Y., Chen, Y., Burman, R. and Zhao, H. (2014), "Second-hand clothing consumption: a cross-cultural comparison between American and Chinese young consumers", International Journal of Consumer Studies, Vol. 38 No. 6, pp. 670-677.

Yan, R.-N., Hyllegard, K. H. and Blaesi, L. F. (2012), "Marketing eco-fashion: The influence of brand name and message explicitness", Journal of Marketing Communications, Vol. 18 No. 2, pp. 151168. 
Yang, S., Song, Y. and Tong, S. (2017), "Sustainable Retailing in the Fashion Industry: A Systematic Literature Review", SUSTAINABILITY, Vol. 9 No. 7, pp. 1266.

Yee, L. W., Hassan, S. H. and Ramayah, T. (2016), "Sustainability and Philanthropic Awareness in Clothing Disposal Behavior Among Young Malaysian Consumers", SAGE Open, Vol. 6 No. 1, pp. $1-10$. 